\title{
Regional evolutions in labor markets in the Philippines: A dynamic approach
}

\author{
Jose G. Montalvo* \\ Department of Economics, Universitat Pompeu Fabra and IVIE, C/Ramón Trias Fargas 25-27, \\ Barcelona 08005, Spain
}

Received 25 February 2005; received in revised form 8 March 2006; accepted 17 April 2006

\begin{abstract}
The basic objective of the article is to provide some evidence on the dynamic adjustment of the Philippines' regional labor markets to shocks. The response of labor markets to a negative labor demand shock is very similar to the findings reported by [Blanchard, O., \& Katz, L. (1992), Regional evolutions. Brookings Papers on Economic Activity, 1, 1-61]. The initial impact is an increase of the unemployment rate and a decrease of the participation rate and employment. Over time the participation and unemployment rates return to their pre-shock levels while employment continues below for some time. The speed of adjustment is faster than in Europe but slower than in the US. However, there are important regional differences in the adjustment process. The second part of the article analyzes the determinants underemployment among Philippines' workers and its regional dimension.
\end{abstract}

(C) 2006 Elsevier Inc. All rights reserved.

JEL classification: $\mathrm{J} 60 ; \mathrm{J} 61$

Keywords: Philippines; Unemployment; Regional labor markets; Underemployment

\section{Introduction}

Asian economies are frequently affected by shocks that disturb their markets. The Asian crisis of 1997-1998 was one of the latest episodes of these type of shocks. The reaction of the labor markets to these shocks is particularly important. However, the analysis should consider not only the reaction at the country level but also at the regional level. The objective of this article is to analyze, from a regional perspective, the dynamic reaction of employment and unemployment to a negative labor demand shock in the Philippines. We also study another important consequence

* Tel.: +34 93542 2509; fax: +34935421746.

E-mail address: montalvo@upf.es. 
of negative labor demand shocks: the microeconomic determinants of regional underemployment.

The structure of the paper is the following. Section 2 reviews the basic characteristics of the Philippines' labor market in comparison with other countries of East Asia and the Pacific area. Section 3 analyzes the evolution of the main labor indicators of the regions of the Philippines with respect to the national average. Section 4 presents a simple model to explain the relationship between labor force participation, employment and unemployment. In the same section we present the estimation of the dynamic effects of adverse labor demand shocks on employment, unemployment and participation rates. We argue that the differences in the evolution by regions is related with the institutions of each regional labor markets. The fifth section analyzes an important phenomenon in the labor market of Philippines: the high proportion of underemployment. Finally, Section 6 present the conclusions.

\section{The Philippines' labor market from the Asian perspective}

The labor market of the Philippines has many idiosyncratic characteristics that make it different from the rest of the countries of Eastern Asia and the Pacific region. ${ }^{1}$ First of all, the rate of unemployment of the Philippines' economy is systematically higher than the average of the countries of the region. Since 1985 the unemployment rate in the Philippines has been close to double the average of the countries of the region. Another feature of Philippines' unemployment is that the proportion of college graduates reaches the $16 \%$ (13\% among men and $21 \%$ among women) and it is increasing. Another important element for the characterization of the labor market is the situation of the youngest cohorts. The first interesting fact is that the unemployment rate among young workers in the age group between 15 and 30 years old is double the rate of the general labor force. This is important since this are the workers with the highest level of education which seems to imply that many of their abilities are depreciated because of their high level of unemployment. The problem is particularly important for women, who have a higher educational level than men. In fact the proportion of college undergraduates and graduates among the young unemployed has increase from $34.6 \%$ in 1998 to $39.5 \%$ in 2002 . The unemployment situation is even worst if we consider only the age group from 15 to 24 years old since their unemployment rate is close to three times the general unemployment rate.

The changes in the labor supply, one of the reasons of the high unemployment rate, are basically related with two factors: the evolution of working age population and the participation rates. On the one hand, the average growth rate of the working age population between 1985 and 2003 has been $2.7 \%$ in the Philippines, very similar to the $2.8 \%$ of Indonesia and Singapore or the $3.1 \%$ of Malaysia. However, in Philippines the growth rate of the working age population before the $1980 \mathrm{~s}$ was $3.6 \%$. Therefore, there has been a clear reduction in the growth rate of working age population. On the other hand, the participation rate of the Philippines has shown an increasing trend although with high volatility, mostly related with external shocks. In 2003 it was around $67 \%$. By gender, the male participation rate in Philippines is one of the highest of the countries considered in the region. Only Myanmar, Lao, Indonesia and China have a higher male participation rate than Philippines. However, the participation rate of women in Philippines is clearly below the average of the region.

\footnotetext{
${ }^{1}$ For a very illuminating and deep description of the main facts about the labor markets in the Philippines see the excellent survey by Orbeta (2002).
} 
The increasing trend of the labor force participation in Philippines during the first part of the 1980s is mostly due to the increasing participation of women, which jumped from 40.13 in 1976 to $47.9 \%$ in 1985 . The participation rate of women stopped growing by the middle of the $1980 \mathrm{~s}$ until the beginning of the 1990s. After that, the growth was slow and volatile but the trend was clearly upwards until reaching 52.2\% in 2001. By contrast the participation rates of males has been stable around $80 \%$.

Finally, the labor market of Philippines is characterized by a high level of underemployment. The National Statistics Office of the Philippines defines an underemployed person as "all employed persons who express the desire to have additional hours of work in their present job or an additional job, or to have a new job with longer working hours."

Therefore, we can conclude that the labor market of Philippines relative to other countries of the region is characterized by three basic facts: a higher participation rate and a higher level of unemployment and underemployment.

\section{Regional labor markets in the Philippines}

The previous section presented a description of the basic variables of the labor market of the Philippines as a whole with respect to other countries in Asia. In this section we consider these variables using a regional perspective. The objective is to compare the evolution of the labor market of each region of the Philippines with respect to the national average.

\subsection{Basic facts}

There are important differences in the evolution of labor markets across the regions of Philippines. For instance Table 1 shows the participation and unemployment rate of each region. ${ }^{2}$ The range of variation in the unemployment rate goes from $4.6 \%$ up to $16.2 \%$, which is a huge difference. In fact the variance is 9 . The participation rate is less variable across regions but still ranges from $57.6 \%^{3}$ up to $74 \%$.

Fig. 1 shows that even considering the Autonomous Region of Mindanao the relationship between unemployment and participation is negative. Eliminating this outlier shows an even steeper negative slope. These data show the interest of the regional dimension in the analysis of labor market interactions and the effect of possibly asymmetric shocks.

There are also important regional differences with respect to productivity. Table 2 shows the productivity of the regions of Philippines in the period 1997-2002 as well as the average. Productivity is measured as the ratio of gross regional domestic product over average employed person (over the four quarterly data).

Obviously there are many reasons for this large difference in productivity ranging from the industrial mixing of the productive structure of each region to the stock of private, public and human capital.

Labor and productivity regional differences do not stop here. The basic institutions of labor markets (like minimum wages, collective bargaining, etc.) show also important regional differences. Table 3 shows the minimum wage (in nominal and real terms) and describes the evolution of purchasing power as a function of the inflation differentials.

\footnotetext{
${ }^{2}$ Appendix A describes the definition of each region in detail.

${ }^{3}$ Notice that in this case there is a religious factor related with the labor participation of women.
} 
Table 1

Participation and unemployment rates by region, October 2003

\begin{tabular}{llr}
\hline & Participation & Unemployment \\
\hline NCR & 66.4 & 16.2 \\
CAR & 69.0 & 7.2 \\
Region I & 64.8 & 10.4 \\
Region II & 69.9 & 4.6 \\
Region III & 64.2 & 11.0 \\
Region IVa & 67.0 & 13.0 \\
Region IVb & 69.3 & 6.2 \\
Region V & 67.2 & 7.1 \\
Region VI & 68.2 & 8.1 \\
Region VII & 65.2 & 11.9 \\
Region VIII & 71.8 & 8.1 \\
Region IX & 65.1 & 5.9 \\
Region X & 74.0 & 6.6 \\
Region XI & 68.5 & 8.9 \\
Region XII & 68.9 & 8.8 \\
ARMM & 57.6 & 5.4 \\
Caraga & 69.5 & 9.1
\end{tabular}

Source: LFS.

The aim of the following sections is to provide a description of some regularities and asymmetries in the regional labor markets in Philippines, and to find some implications for the importance of migration across regions. The analysis concentrates in the evolution of employment and unemployment. The analysis is based on quarterly data from the

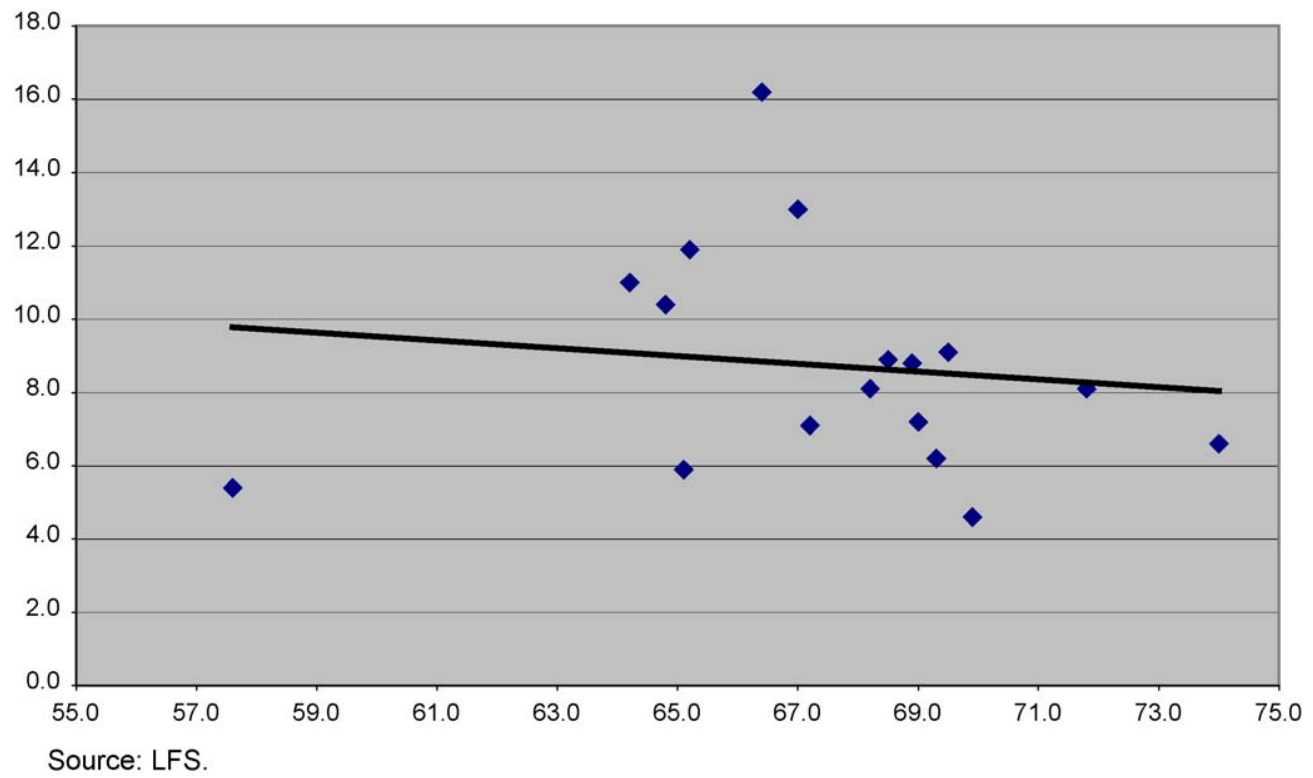

Fig. 1. The relationship between regional unemployment and labor market participation. 
Table 2

Productivity by regions (at constant prices of 1985)

\begin{tabular}{|c|c|c|c|c|c|c|c|}
\hline Region & 1997 & 1998 & 1999 & 2000 & 2001 & 2002 & Average \\
\hline Philippines total & 32226 & 31814 & 33096 & 35442 & 34357 & 34798 & 33902 \\
\hline NCR Metro Manila & 77116 & 75517 & 75722 & 82484 & 80668 & 81867 & 79252 \\
\hline CAR Cordillera & 35650 & 36714 & 45338 & 47240 & 45639 & 46310 & 44248 \\
\hline Ilocos Region & 16947 & 18347 & 18618 & 19509 & 19445 & 20456 & 19275 \\
\hline Cagayan Valley & 15024 & 14420 & 18752 & 20277 & 19578 & 19186 & 18443 \\
\hline Central Luzon & 33467 & 30420 & 30527 & 32718 & 31875 & 31791 & 31466 \\
\hline Southern Tagalog & 38074 & 36987 & 35293 & 37154 & 35419 & 36946 & 36360 \\
\hline Bicol Region & 13252 & 12956 & 15439 & 16122 & 15678 & 16333 & 15306 \\
\hline Western Visayas & 25215 & 25188 & 28209 & 30129 & 29689 & 29326 & 28508 \\
\hline Central Visayas & 29462 & 30017 & 31576 & 33992 & 34843 & 34843 & 32970 \\
\hline Eastern Visayas & 14133 & 14257 & 16019 & 17016 & 15868 & 15586 & 15749 \\
\hline Western Mindanao & 23171 & 23848 & 23740 & 24944 & 23882 & 23632 & 24009 \\
\hline Northern Mindanao & 33532 & 28258 & 30052 & 32656 & 31254 & 24666 & 29377 \\
\hline Southern Mindanao & 25229 & 29052 & 28935 & 31213 & 29749 & 42342 & 32261 \\
\hline Central Mindanao & 26464 & 25741 & 24921 & 26926 & 25398 & 20718 & 24741 \\
\hline ARMM & 13043 & 13058 & 12772 & 12791 & 12582 & 12211 & 12683 \\
\hline CARAGA & 15966 & 14861 & 15562 & 17807 & 16555 & 16376 & 16232 \\
\hline
\end{tabular}

Table 3

Regional differences in the nominal and real minimum wage

\begin{tabular}{llr}
\hline REGION & Minimum wages, January 2004 & Real wage \\
\cline { 2 - 3 } & Nominal wage & 155.90 \\
\hline NCR & 280.00 & 111.90 \\
CAR & 190.00 & 112.69 \\
I & 190.00 & 111.65 \\
II & 185.00 & 132.85 \\
III & 228.50 & 134.35 \\
IV & 237.00 & 98.11 \\
V & 182.00 & 110.02 \\
VI & 180.00 & 107.35 \\
VII & 200.00 & 106.94 \\
VIII & 188.00 & 102.22 \\
IX & 175.00 & 107.80 \\
X & 192.00 & 115.45 \\
XI & 195.00 & 110.84 \\
XII & 180.00 & 104.62 \\
CARAGA & 179.00 & 71.21 \\
ARMM & 140.00 & \\
\hline
\end{tabular}

Labor Force Survey, from 1992 to the last quarter of $2002 .{ }^{4}$ The unemployment and participation rates by region are calculated using the adjusted weights provided by the NSO in the LFS files. The same adjustment is used to aggregate employment across areas in each region.

\footnotetext{
${ }^{4}$ Unfortunately we could not use the data from 1988 to 1991 since there were many doubts about their integrity and representativeness. We calculated the rates using the microdata for all quarters provided by the NSO.
} 


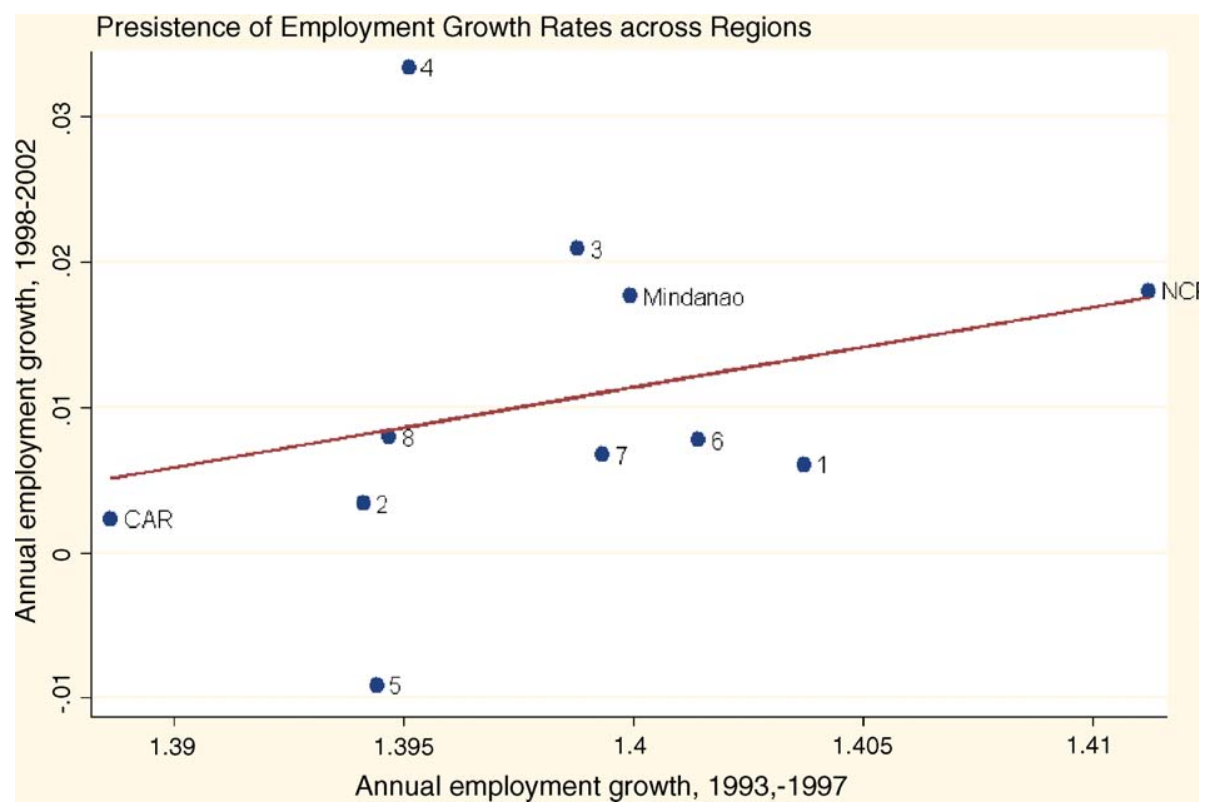

Fig. 2. Persistence of employment growth (yearly data)

\subsection{Basic trends in relative employment}

In this subsection we analyze the evolution of regional employment in comparison with the national average. The first issue is to check if there is persistence of employment growth rates across regions. The Asian crisis of 1997 provides a natural breaking point. Therefore, Fig. 2 presents the relationship between the average growth rate of employment before the Asian crisis and after. The line illustrated in Fig. 2 has a positive slope coefficient, and a $R^{2}$ of $0.16 .^{5}$

Philippines' regions experienced in the last decade quite different rates of employment growth. Figs. 3-7 show the evolution of cumulative employment growth across time per regions, where cumulative employment growth is defined as the cumulated change in log employment minus its value at the beginning of the period, and employment for each region is the $\mathrm{NSO}^{6}$. standard employment, calculated in deviation from national mean. We have grouped the eleven regions ${ }^{7}$ in three main groups depending on the relative performance.

Even though we do not see in the data any experience of decisive and strong growth - these are the years of the Asian slowdown - we can clearly identify four regions displaying an appreciable surge in employed labor force, especially during the last years. These regions (see Fig. 3) are

\footnotetext{
${ }^{5}$ This result is very similar to the one presented in Decressing and Fatas (1995) for Europe (p. 1635). In fact the coefficient of determination is identical.

${ }^{6}$ We choose the National Statistical Office (NSO) definitions because we have more complete series than those collected according with ILO definitions, which are missing in several quarters of the Labor Force Survey.

${ }^{7}$ Given that after June 1996 and in 2002 the division of some regions changed, we have aggregated Western Mindanao (Region 9), Northern Mindanao (Region 10), Southern Mindanao (Region 11), Central Mindanao (Region 12), ARMM and CARAGA into one single region, called Mindanao, in order to have a common area before and after the change. Appendix A presents a detailed exposition of the construction of the different regions used in this analysis.
} 


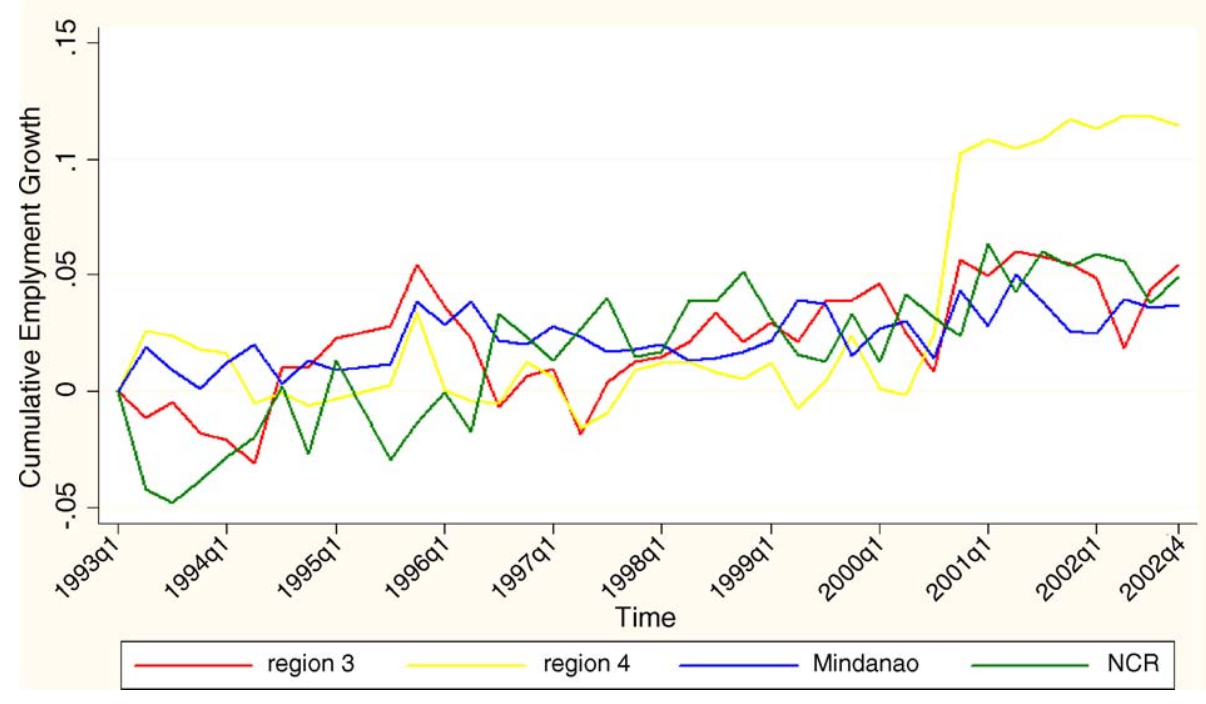

Fig. 3. Cumulative employment growth in deviation for the national growth. Winners.

Central Luzon (Region 3), Calabarzon and Mimaropa (Region 4), Mindanao in the south west, and NCR, Manila. Note that the first two are close to each other and are all around the capital Manila while the last is located in the south.

Fig. 4 shows the cumulative growth of those regions which performed slightly below their score at the beginning of the sample period. Note that either Ilocos Region (Region 1) in the north west, and the other two regions, Western Visayas and Central Visayas (Regions 6 and 7) display a slightly better performance than their close neighbours, the Cagayan Valley (Region 2) and

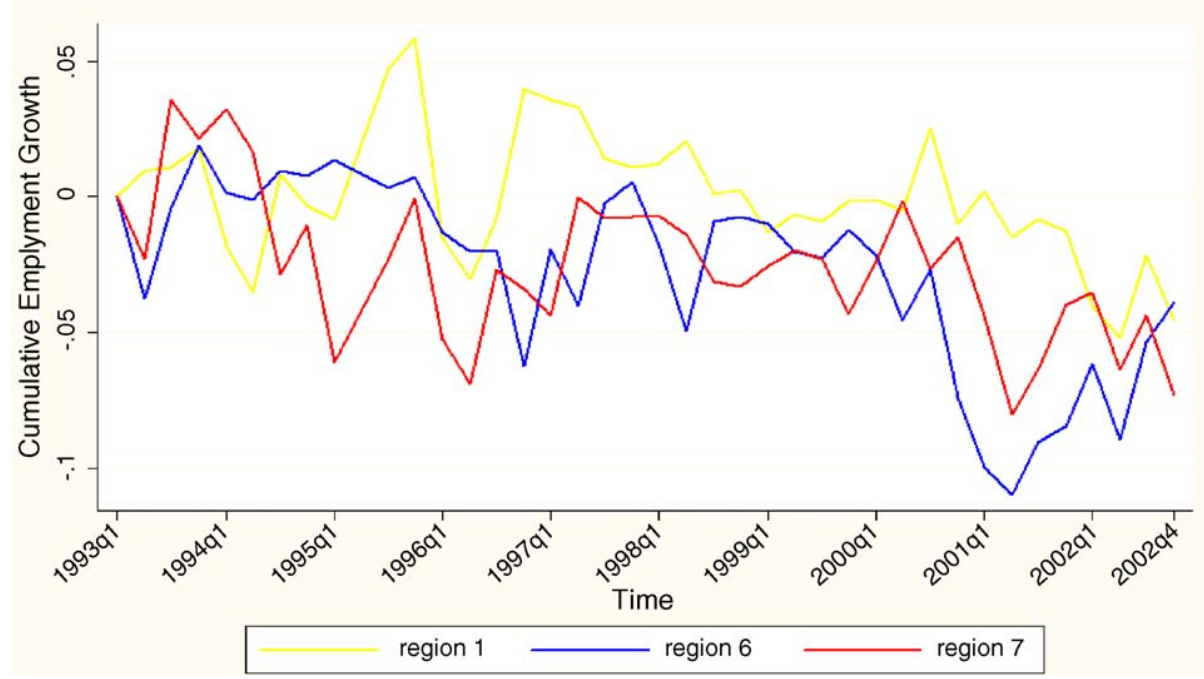

Fig. 4. Cumulative employment growth in deviations from the national mean. Losers. 


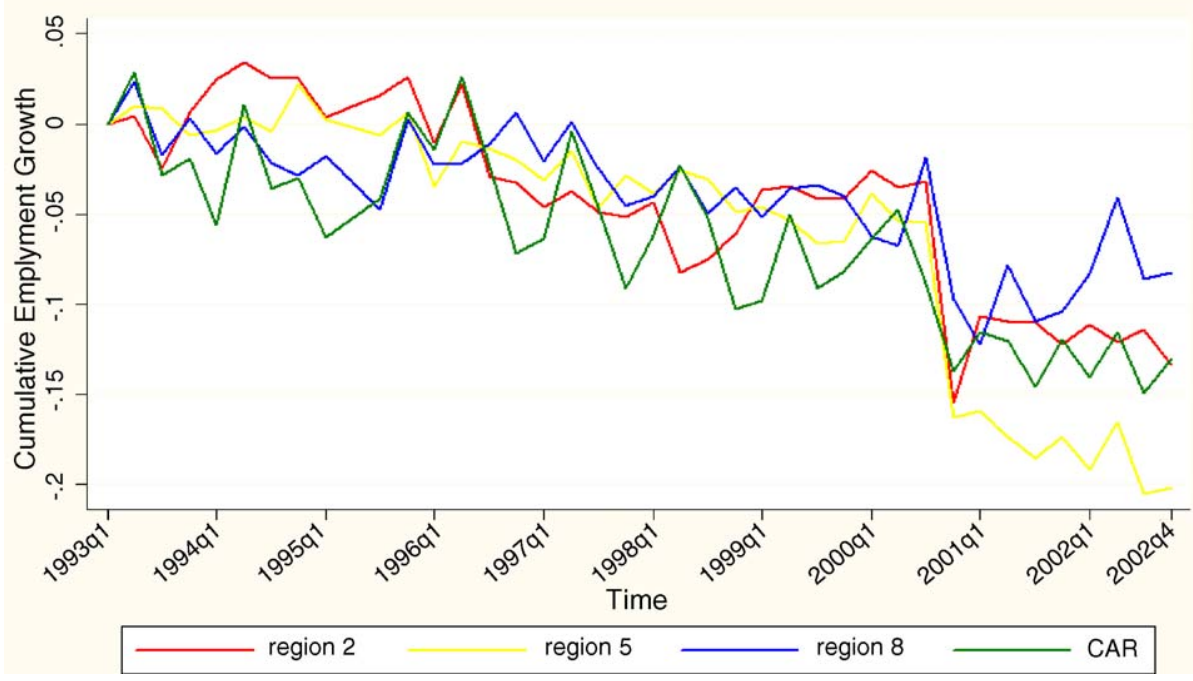

Fig. 5. Cumulative employment growth in deviations for the national mean. Heavy losers.

Eastern Visayas (Region 8), respectively, which we award the label of heavy losers in the next graph (Fig. 5). This confirms a general trend toward a fall in employment in the Philippines during the 1990 s.

Much clearer is the deep fall (see Fig. 5) of four regions which appear to have been loosing jobs all along the decade with a particularly severe slow down in October 2000. These are Cagayan Valley (Region 2), in the far north east, Bicol Region (Region 5) and Eastern Visayas (Region 8), in the central Philippines just below the regions around Manila, and CAR.

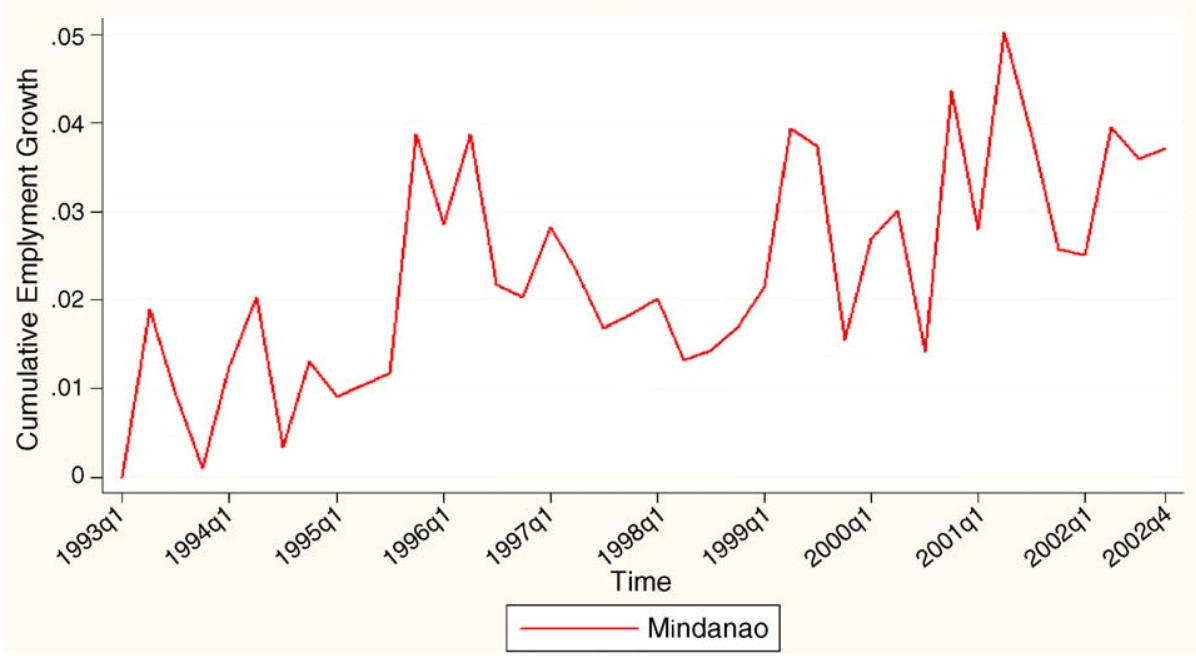

Fig. 6. Cumulative employment growth in deviation from the national mean. Mindanao. 


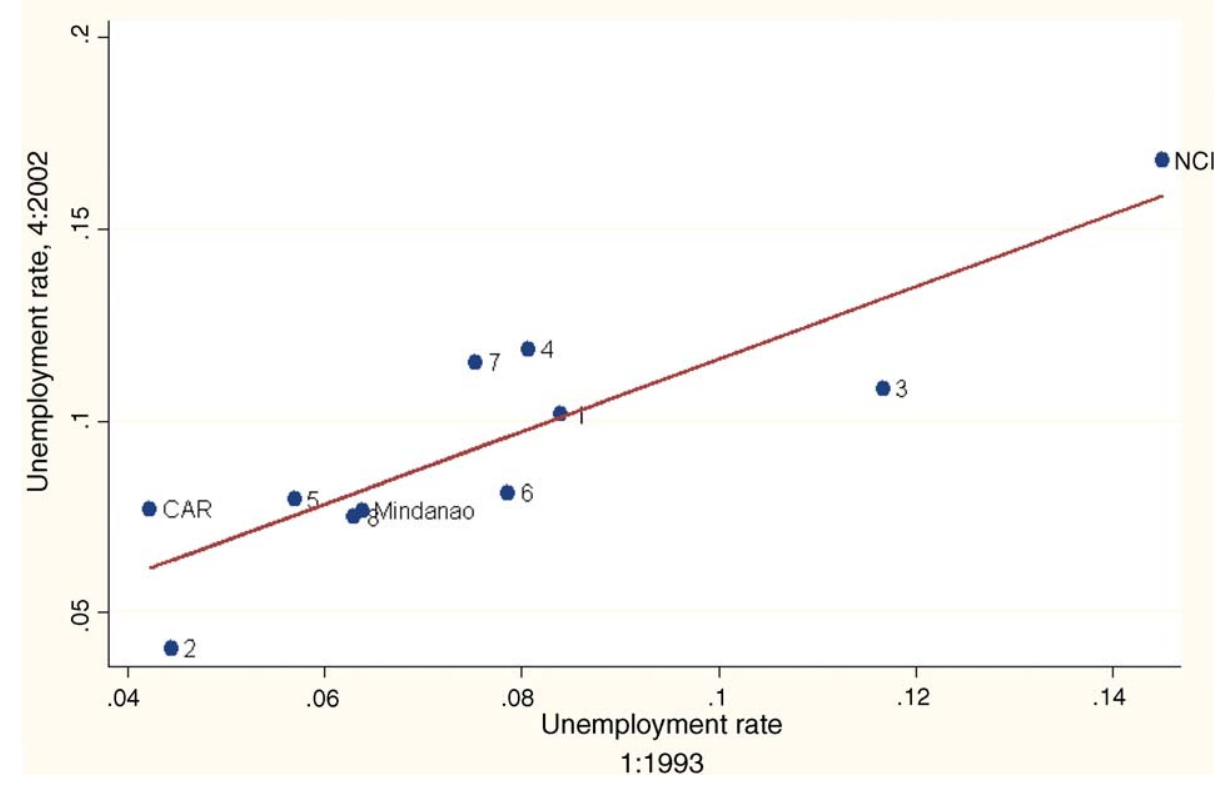

Fig. 7. The persistence of unemployment across regions.

The evolution of employment by geographic areas can be better understood by grouping regions according to the administrative repartition of the country in three main or wide areas: Luzon, in the north (which includes Manila), Visayas, in the centre, and Mindanao, in the south (Fig. 6). ${ }^{8}$ The last decade has witnessed the surge of the south, the dramatic fall of the centre and a irregular (high variability across regions) performance of the north.

\subsection{Basic trends in relative unemployment}

After looking at employment we turn now to the description of relative unemployment. The following figures are intended to provide some intuition about movements and trends in regional unemployment.

The straight line in Fig. 7, with a significant coefficient $\beta=0.758$ and an $R^{2}=0.76$, reveals a noticeable persistence in unemployment rate across regions, that is regions tend to have a quite stable unemployment rate. However, the slope less than one suggests that there is a general trend toward improvement in unemployment. In other words, Philippines' regions seem to have improved altogether remaining in 2002 at almost the same relative positions they were in 1993.

We can compare the previous result with similar analyses done for the case of Europe and the US. In the European case the slope is 1.09 and the $R^{2}$ is $0.23 .^{9}$ For the US the slope is 0.67 and the $R^{2}$ is equal to 0.38 . Therefore, the differences in regional unemployment rates across regions

\footnotetext{
${ }^{8}$ We do not include the graphs for the area of Luzon and Visayas to avoid an excess of graphs. This information can be obtained directly from the author.

${ }^{9}$ Decressing and Fatas (1995), p. 1638.
} 


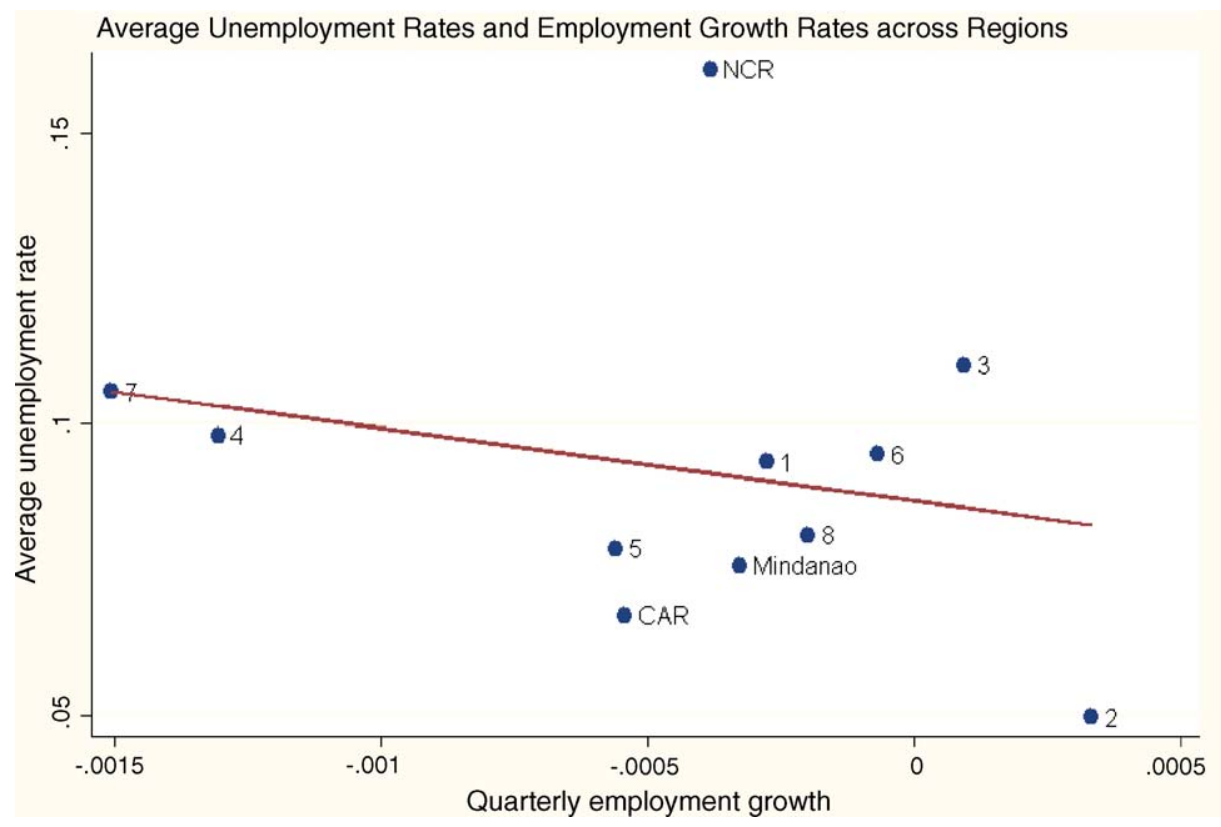

Fig. 8. The relationship between regional unemployment and employment growth.

seem to be more persistent in Europe than in the US or the Philippines. This is reasonable since Europe is not an integrated labor market yet. ${ }^{10}$

We can connect the previous two sections by analyzing the growth rate of employment and the level of unemployment. In principle, the correlation between mean unemployment rates and employment growth rates depends on the relative importance of the underlying sources of growth. If growth is demand-driven we should observe a negative correlation between average unemployment and employment growth; the opposite should hold if growth is driven by changes in labor supply caused by workers' migration. Fig. 8 presents the relationship between employment growth and average unemployment. The slope is negative but statistically insignificant. In addition the $R^{2}$ is equal to 0.05 . The persistence of unemployment could be explained by the effect of inappropriate institutions, or labor market rigidities (Blanchard \& Wolfers, 2000). We will discuss this issue in the next section.

\subsection{Common versus state-specific changes in employment}

It is important to understand how much of the typical movement in regional employment is common to all regions and how much is region-specific. To answer this question, we run the following regression for each region:

$$
\Delta N_{i t}=\alpha_{i}+\beta_{i} \Delta N_{t}+\varepsilon_{i t}
$$

\footnotetext{
${ }^{10}$ Bayoumi and Prasad (1995) find also that inter-regional mobility appears to be more important, as an adjustment mechanism, in the US which has a more integrated labor market than Europe.
} 
where $N_{i t}$ is the logarithm employment rate in region $i$ at time $t$ and $N_{t}$ is the same figure at the national level. We regress two specifications, using both the employment rate calculated as share of the working age population and as the share of the labor force. Tables 4 and 5 report the standard error and the $t$-test for the betas being equal to 1 .

The first result is that in both cases the parameters estimated are highly significant and range between 0.67 and 1.85 in the first, and between 0.39 and 2.24 in the second table, indicating a clearly positive relation between regional and national employment movement.

To what extent the overall movement explains the regional evolution? This depends on the $R^{2}$ of the regressions. As we can see in Table 4, much of the year-to-year movement of the regional employment - when measured as a fraction of working age population - seems to be explained by movements in national employment. Nevertheless, when we calculate employment as a fraction of the labor force, we get a quite different result: although the direction of the relation is the same, it appears to be much more volatile across regions and to be much weaker than before-the $R^{2}$ is considerably lower in all the regressions. This finding may well be due to migration from regions to abroad during bad times instead of internal migration (between regions): indeed, a negative shock to a region's economy determining a loss of labor force moving from the region to abroad - and an analogous loss of employed people - has a much higher impact over a region's economy than over the national overall figures. On the other hand, when dealing with working age population, this effect is much lower because the working age population is a bigger figure and only a part of it is willing to migrate. Therefore, its movements are proportionally smaller and the relation between regional and national movements appears to be less strict.

A third point to be noted is that for five regions in the first case and four in the second - Region 7 being the only one common to both regressions - the null of a one-to-one comovement cannot be rejected so that we shall consider them moving in line with the overall performance of the Philippines.

\section{The dynamics of regional labor markets in response to demand shocks}

In this section we analyze the response of regional labor markets to demand shocks. When there is an adverse shock in labor demand the response takes place through two adjustment mechanisms. The reduction in real wages caused by this adverse shock attracts firms to the region but, at the same time, triggers the out-migration of labor. The long-run effect on employment depends on the relative strength and speed of these two effects. Our goal in this section is to estimate the long-run effect of a negative shock on labor demand on level of employment, the unemployment rate and the participation rate, measuring also the implied effect on migration. ${ }^{11}$

To clarify these mechanisms, and serve as a support for the empirical specification, it is convenient to lie down a simple model like in Blanchard and Katz (1992). Let us assume a production function with constant returns to scale and a downward sloping labor demand curve. If labor market is not in full employment we can write the labor demand function as

$$
w_{i t}=-\alpha_{1}\left(n_{i t}-u_{i t}\right)+z_{i t}
$$

\footnotetext{
${ }^{11}$ For an intuitive view of this process the reader can also refer to Shield and Novak (2000).
} 
Table 4

Regressions relating regional employment growth to national employment growth (employment as share of working age population)

\begin{tabular}{|c|c|c|c|c|c|c|c|c|c|c|c|}
\hline & Region 1 & Region 2 & Region 3 & Region 4 & Region 5 & Region 6 & Region 7 & Region 8 & NCR & CAR & Mindanao \\
\hline Coefficient $(\beta)$ & $0.826^{* *}(0.091)$ & $1.556^{* *}(0.130)$ & $0.696^{* *}(0.107)$ & $0.509^{* *}(0.053)$ & $1.187^{* *}(0.069)$ & $1.854^{* * *}(0.088)$ & $1.058^{* *}(0.086)$ & $1.395^{* *}(0.140)$ & $0.857^{* *}(0.086)$ & $0.0875^{* *}(0.105)$ & $1.000^{* * *}(0.031)$ \\
\hline Constant & $0.000(0.002)$ & $0.001(0.003)$ & $0.000(0.002)$ & $-0.001(0.001)$ & $0.000(0.001)$ & $0.001(0.002)$ & $-0.001(0.002)$ & $0.000(0.003)$ & $0.000(0.002)$ & $-0.000(0.002)$ & $0.000(0.001)$ \\
\hline$R$-squared & 0.70 & 0.80 & 0.55 & 0.72 & 0.89 & 0.93 & 0.81 & 0.74 & 0.74 & 0.66 & 0.97 \\
\hline $\begin{array}{l}\text { Test } F(\beta=1), \\
\quad \text { probability }>F\end{array}$ & $3.68(0.06)$ & $18.26(0.00)$ & $8.02(0.01)$ & $85.59(0.00)$ & $7.35(0.01)$ & $95.06(0.00)$ & $0.46(0.50)$ & $7.92(0.01)$ & $2.78(1.00)$ & $1.41(0.24)$ & $0.00(1.00)$ \\
\hline
\end{tabular}

Common movements in regional employment growth. Standard errors in parentheses; ${ }^{*}$ significant at $5 \%$; ${ }^{* *}$ significant at $1 \%$; observations: 37 for each regression. 
Table 5

Regressions relating regional employment growth to national employment growth (employment as share of labor force)

\begin{tabular}{|c|c|c|c|c|c|c|c|c|c|c|c|}
\hline & Region 1 & Region 2 & Region 3 & Region 4 & Region 5 & Region 6 & Region 7 & Region 8 & NCR & CAR & Mindanao \\
\hline Coefficient $(\beta)$ & $0.571^{*}(0.214)$ & $1.676^{* *}(0.222)$ & $0.716^{* *}(0.162)$ & $0.908^{* *}(0.222)$ & $1.532^{* *}(0.174)$ & $0.582^{*}(0.236)$ & $0.862^{* *}(0.248)$ & $1.545^{* *}(0.270)$ & $0.391^{* *}(0.186)$ & $2.237^{* *}(0.338)$ & $1.385^{* *}(0.110)$ \\
\hline Constant & $-0.001(0.002)$ & $-0.001(0.002)$ & $0.001(0.002)$ & $-0.000(0.001)$ & $-0.001(0.002)$ & $0.001(0.002)$ & $-0.001(0.002)$ & $0.001(0.003)$ & $0.001(0.002)$ & $-0.002(0.003)$ & $0.000(0.001)$ \\
\hline$R$-squared & 0.17 & 0.62 & 0.36 & 0.61 & 0.69 & 0.15 & 0.26 & 0.48 & 0.11 & 0.56 & 0.82 \\
\hline $\begin{array}{l}\text { Test } F(\beta=1) \\
\quad \text { probability }>F\end{array}$ & $4.00(0.05)$ & $9.30(0.00)$ & $3.07(0.09)$ & $0.57(0.45)$ & $9.33(0.00)$ & $3.15(0.08)$ & $0.31(0.58)$ & $4.08(0.05)$ & $10.76(0.00)$ & $13.37(0.00)$ & $12.26(0.00)$ \\
\hline
\end{tabular}

Common movements in regional employment growth. Standard errors in parentheses; * significant at 5\%; ${ }^{* *}$ significant at 1\%; observations: 37 for each regression. 
where $w$ is the relative wage of region $i$ with respect to the average of the Philippines, $n$ the logarithm of the labor force in region $i$ at time $t$ with respect to the average, and $u$ is the unemployment rate. ${ }^{12}$ The difference between $n$ and $u$ is approximately equal to the logarithm of employment. The variable $z$ represents the position of the labor demand curve. Obviously, it should be the case that wages are negatively related with unemployment:

$$
w_{i t}=-\frac{1}{\alpha_{2}} u_{i t}
$$

The model is closed by specifying the dynamic evolution of the position of the demand and supply curve. The change the demand and the supply of labor is characterized by the following processes:

$$
z_{i t+1}-z_{i t}=-\alpha_{3} w_{i t}+d_{i}+\varepsilon_{i t}^{\mathrm{d}}, \quad n_{i t+1}-n_{i t}=\alpha_{4} w_{i t}-\alpha_{5} u_{i t}+s_{i}+\varepsilon_{i t}^{\mathrm{s}}
$$

where $d(s)$ is a drifts in relative labor demand (supply) and $\varepsilon^{\mathrm{d}}\left(\varepsilon^{\mathrm{s}}\right)$ represents a white noise shock in demand (supply). As expected labor demand is negatively related with wages while higher wages increase labor supply. The drift in demand represents the ability of some regions to attract new industries while other regions cannot do it. Given wages, the demand curve shifts in function of the drift in relative labor demand $(d)$ and the demand shock $\left(\varepsilon^{\mathrm{d}}\right)$. Since unemployment has two opposite effects on the movements of the labor demand curve given wages it is not included as a determinant of labor supply. Notice that higher unemployment implies a large pool of workers to choose from, what attracts firms, but also increases the migration of workers. On the other hand, given wages, the supply shifts with the supply drift $(s)$, the changes in unemployment $(u)$ and the innovations to labor supply $\left(\varepsilon^{\mathrm{s}}\right) .^{13}$

Let us consider an economy that works following the equations of the model described above. Imagine that there is a negative innovation in the relative demand for labor. In response to an adverse shock to labor demand an instantaneous downward adjustment of wages takes place and unemployment increases. As a consequence, two driving forces determine the new equilibrium. On one side, workers tend to migrate to other regions while firms, attracted by the lower wages, move into the shocked region. Depending on the relative speed and magnitude of the two adjustment processes, the reduction in the employment level can be more or less severe. $^{14}$

Over time, the attraction of firms and the migration of workers will reduce unemployment and increase wages. Since the attraction of firms (demand for labor) does not depend on unemployment, only lower wages can attract firms while both (lower wages and higher unemployment) affect the migration of workers. For this reason, if the initial decline in demand is reflected in a large increase in unemployment, then the effect on employment will last for a long time.

This is the basic mechanism of the model. However, as most of the economic models, the theory is unable to provide a precise characterization of the timing of the effects. In addition, the relative importance of the effect of attraction of firms and migration of workers depends on the empirical elasticities of demand and supply. To evaluate the relative strength of each effect we

\footnotetext{
${ }^{12}$ All the $\alpha$ 's in the model are positive.

13 This relationship is compatible with standard microeconomic models of labor demand and supply.

${ }^{14}$ This is also important from the point of view of reducing poverty since, poverty and unemployment are very closely related. In addition a very recent paper by Manlagñit (2004) has noticed that many economically active household members can alleviate poverty.
} 
need to estimate the empirical short run and long run impact of adverse labor demand shocks on employment, participation and unemployment. Blanchard and Katz (1992) propose a reduce form VAR specification to analyze the response of these variables to labor demand shocks. Following their VAR specification we estimate a log linear system in three variables: $\Delta e_{i}{ }^{15}$ is the first difference of the logarithm of employment in region $i$, minus the first difference of the logarithm of Philippines aggregate unemployment. The second, $l e_{i}$, is the logarithm of the ratio between employment to the labor force in the region $i$, minus the same variable for the entire Philippines. The third $l p_{i}$ is the logarithm of the ratio between the labor force to the working age in region $i$ in deviation from the national average. From the behaviour of these three variables we can easily compute the effect on the unemployment and the participation rate. ${ }^{16}$ The precise specification is ${ }^{17}$

$$
\begin{gathered}
\Delta e_{i t}=\alpha_{i 10}+\alpha_{i 11}(L) \Delta e_{i, t-1}+\alpha_{i 12}(L) l e_{i, t-1}+\alpha_{i 13}(L) l p_{i, t-1}+\varepsilon_{i e t}, \\
l e_{i t}=\alpha_{i 20}+\alpha_{i 21}(L) \Delta e_{i, t}+\alpha_{i 22}(L) l e_{i, t-1}+\alpha_{i 23}(L) l p_{i, t-1}+\varepsilon_{i u t}, \\
l p_{i t}=\alpha_{i 30}+\alpha_{i 31}(L) \Delta e_{i, t}+\alpha_{i 32}(L) l e_{i, t-1}+\alpha_{i 33}(L) l p_{i, t-1}+\varepsilon_{i p t}
\end{gathered}
$$

We allow for two lags of each variable. This identification strategy implies that current changes in $\Delta e_{i}$ affect both $l e_{i}$ and $l p_{i}$, but not vice versa. Therefore, $\varepsilon_{i e}$ has to be interpreted as a shock in labor demand. It is reasonable to assume that unexpected movements in employment within the quarter reflect movements in labor demand. ${ }^{18}$

The impulse-response graphs show that, in general, a negative shock to labor demand produces the following effects: immediately after the shock, the participation rate decreases, the unemployment rate increases and the level of employment drops. In Table 6, we have computed the implied effect on net out migration of a reduction of employment of one worker. In the first year, on average, ${ }^{19}$ a reduction of one worker leads to an increase in unemployment of 0.08 units, a decrease in participation of 0.47 workers and an implied migration of 0.44 workers.

The effect on participation and unemployment rate declines and finally disappears after five to eight quarters. On the other hand the effect on the level of employment reaches on average a plateau of -0.49 .

However, we note sensible differences across regions: in the first period the impact on migration is much lower in the National Capital Region than in the other regions, while there is a wide variation in the "long-run" effect on the level of employment: indeed the range of variation goes from a value of -1.73 in Region 2 to values not significantly different from zero in other regions.

\footnotetext{
${ }^{15}$ We obtained this variable in the following way: $\Delta e_{i}=\left(\ln \frac{E_{i t}}{W_{i t}}-\ln \frac{E_{t}}{W_{t}}+\ln \frac{W_{i t}}{W_{t}}\right)-\left(\ln \frac{E_{i, t-1}}{W_{i, t-1}}-\ln \frac{E_{t-1}}{W_{t-1}}+\ln \frac{W_{i, t-1}}{W_{t-1}}\right)$, where $W_{i t}$ and $E_{i t}$ are the working-age population and the number of employee in state $i$, in time $t$, respectively, and the variable without the subscript $i$ represent the corresponding national aggregation.

${ }^{16}$ Indeed we can compute $\mathrm{d}(U / L)=(E / L)(\mathrm{d} \ln (L / E))$ and $\mathrm{d}(L / W)=(L / P)(\mathrm{d} \ln (L / P))$, where $U, L, E$, and $\mathrm{W}$ are unemployment, the labor force, employment, and working age population, respectively. The mean value for the sample of $E / L$ is 0.9019 and for $L / P$ is 0.6906 .

${ }^{17}$ This is the same specification proposed originally by Blanchard and Katz (1992) and used by Decressing and Fatas (1995) and Shield and Novak (2000).

${ }_{18}$ This assumption is the same used by Blanchard and Katz (1992) and Decressing and Fatas (1995).

${ }^{19}$ We used the share of population in each single region over the total population as weights.
} 
Table 6

Implied effect on out-migration in the first quarter of a reduction of one worker

\begin{tabular}{lccc}
\hline Region & Out of labor force & Unemployment & Implied out migration \\
\hline Region 1 & 0.67 & 0.18 & 0.15 \\
Region 2 & 0.11 & -0.04 & 0.93 \\
Region 3 & 0.59 & 0.22 & 0.18 \\
Region 4 & 0.04 & -0.26 & 1.22 \\
Region 5 & -0.39 & -0.15 & 1.54 \\
Region 6 & 0.26 & 0.41 & 0.33 \\
Region 7 & 0.64 & 0.23 & 0.12 \\
Region 8 & 0.91 & 0.00 & 0.09 \\
Mindanao & 0.73 & -0.02 & 0.29 \\
NCR & 0.65 & 0.34 & 0.01 \\
CAR & 0.74 & 0.11 & 0.15 \\
Average $^{\mathrm{a}}$ & 0.47 & 0.08 & 0.44 \\
\hline
\end{tabular}

Source: author calculations based on the impulse response functions.

${ }^{\text {a }}$ See foonote 7 .

Fig. 9 presents the dynamic impact of a negative shock in the demand of labor on regional employment, participation rates and unemployment rates. With one exception, all the regions behave as predicted by the model. The negative shock increases unemployment and decreases participation contemporaneously. Employment is also negatively affected. Over time the unemployment and the participation rates come back to their previous levels while employment remain below its initial level.

However, the most interesting effect is the differential dynamic behaviour of the regions. We notice that in regions where the minimum wages are high the recovery of the unemployment rate takes very long (more than eight quarters) while in regions where the minimum wages are low this effect is seen in two or three quarters. These finding are consistent with the results of Blanchard and Wolfers (2000). They argue that the evolution of unemployment in Europe cannot be explained only by the effect of shocks or labor market rigidities. Blanchard and Wolfers (2000) focus in the interaction between adverse shocks and adverse market institutions. Some institutions have an important effect on the impact of shocks on unemployment. If minimum wages are too high then an increase in unemployment due to an adverse shock reduces the pressure of unemployment on wages. ${ }^{20}$ This would slow the return to lower unemployment. This is exactly what we observe by comparing regions with high/low minimum wages in Fig. 9.

One would expect to see different dynamic evolution to negative shock in function of the minimum wages of each region. As we saw in Table 3 there is a large variability in minimum wages across regions in Philippines. The most dramatic behaviour observed in unemployment and employment after a negative shocks happens in NCR where, at the same time, we observe the highest minimum wage ( 280 pesos). The other region that shows a very slow recovery of unemployment and participation rates is Central Luzon which present also one of the highest levels of minimum wages (228.5 pesos). Obviously, these pieces of evidence are not enough to assert positively that minimum wages are the cause of the slow adjustment to the adverse labor demand shocks in some regions of the Philippines. There are not enough observations of regional

\footnotetext{
${ }^{20}$ Blanchard (2006) gives an assessment of the current level of understanding of the relationship between labor market institutions and shocks.
} 
difference in minimum wages to attempt a more systematic analysis. However, the fragmentary evidence we provide points in that direction.

Fig. 9 presents the dynamic impact of a negative shock in the demand of labor on regional employment growth, participation rates and unemployment. With one exception all the regions behave as expected by the model. The negative shock increases unemployment and decreases participation contemporaneously. Employment is also negatively affected. Over time the unemployment and the participation rates come back to their previous levels while employment remain below its initial level.

However, the most interesting effect is the differential dynamic behaviour across regions. It is quite interesting to notice that in regions where the minimum wage is high the recovery of the unemployment rate takes very long (more than eight quarters) while in regions where the minimum wage is low this effect is seen in two or three quarters.

These finding are consistent with the findings in Blanchard and Wolfers (2000). They argue that the evolution of unemployment in Europe cannot be explained only by the effect of shocks or labor market rigidities. Blanchard and Wolfers (2000) focus in the interaction between adverse shocks and adverse market institutions. Some institutions have an important effect on the impact of shocks on unemployment. If minimum wages are too high then an increase in unemployment due to an adverse shock reduces the pressure of unemployment on wages. This would slow the return to lower unemployment. This is exactly what we observe by comparing regions with different minimum wages in Fig. 9.

One would expect to see different dynamic evolution to negative shocks in function of the minimum wages of each region. As we saw in Table 3 there is a large variability in minimum wages across regions in Philippines. The most dramatic behaviour observed in unemployment and employment after a negative shocks happens in NCR where, at the same time, we observe the highest minimum wage ( 280 pesos). The other region that shows a very slow recovery of

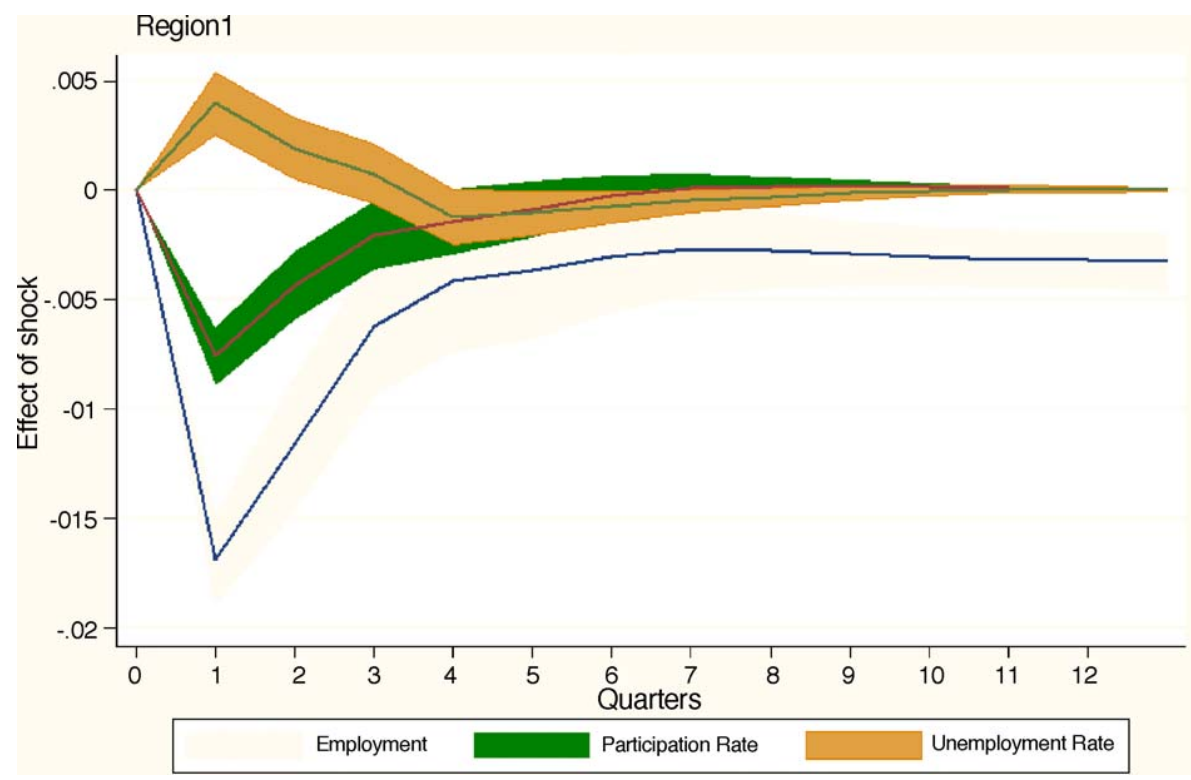

Fig. 9. Response of employment, unemployment, and labor force to an employment shock, by regions. 

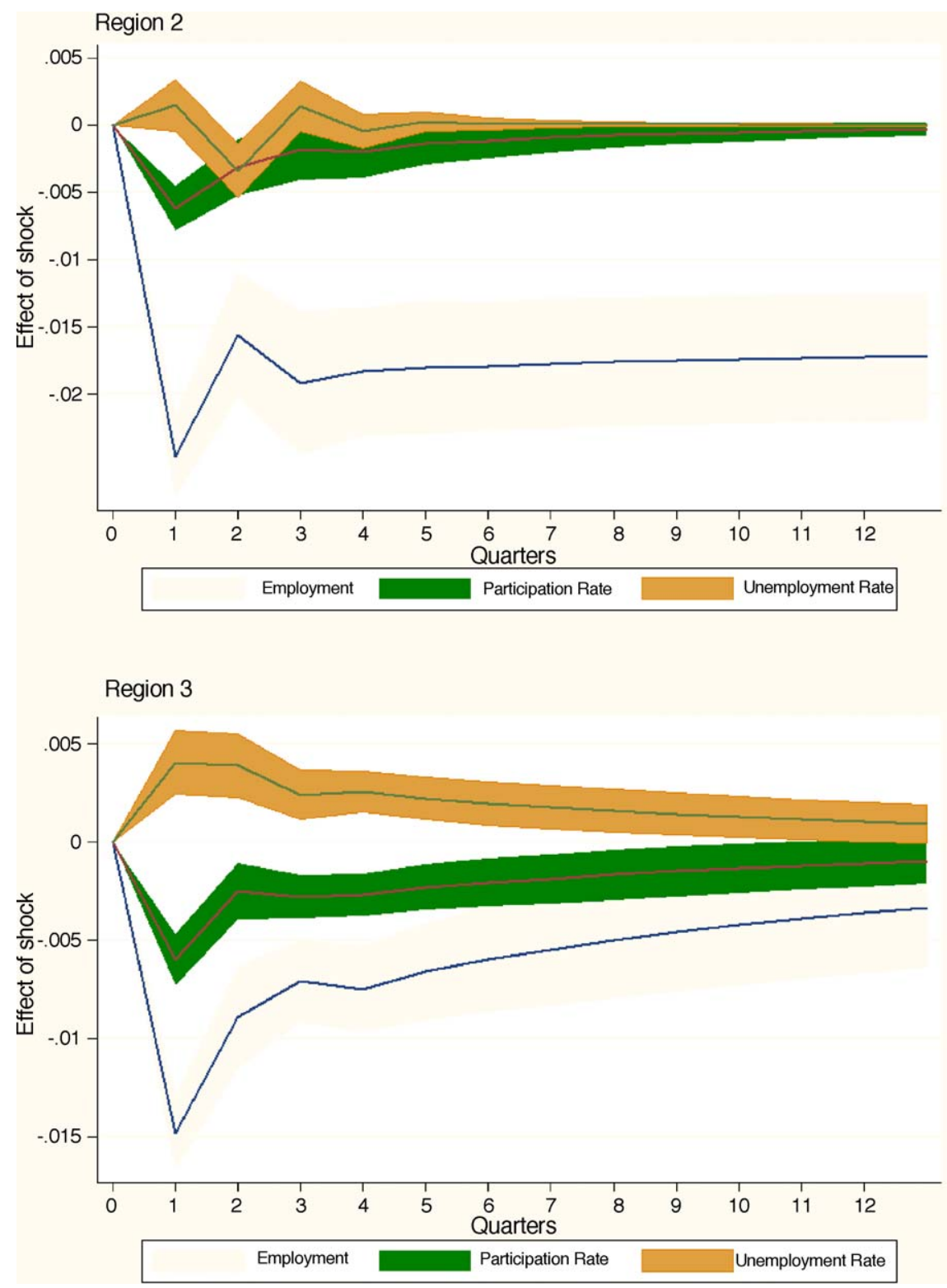

Fig. 9. (Continued)

unemployment and participation rates is Central Luzon which present also one of the highest levels of minimum wages (228.5 pesos). Obviously, these pieces of evidence are not enough to assert positively that minimum wages are the cause of the slow adjustment to the shocks in the labor market of Philippines. There are not enough observations of regional difference in minimum wages to attempt a more systematic analysis. However, the fragmentary evidence we have provided points in that direction. 

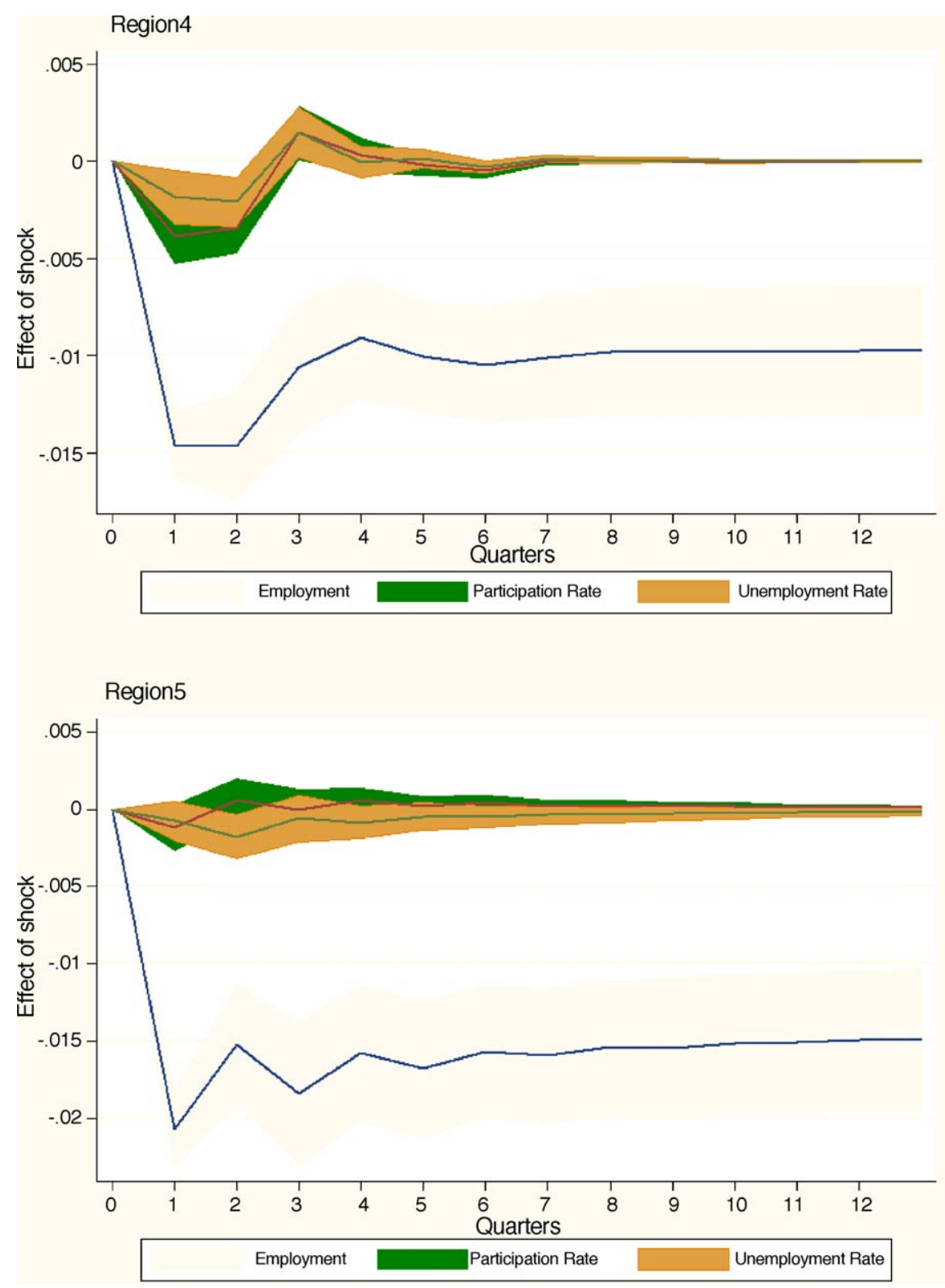

Fig. 9. (Continued)

Fig. 9 shows that in the NCR the unemployment rate initially increases when there is a negative shock and it takes between six and seven quarters to recover. Employment takes some time to recover but, opposite to what happen in other regions, after 2 years it has almost recover the pre-shock level. In Luzon we observe something similar, although it takes longer to recover the pre-shock unemployment rate. In addition the employment do not recover the pre-shock level. 

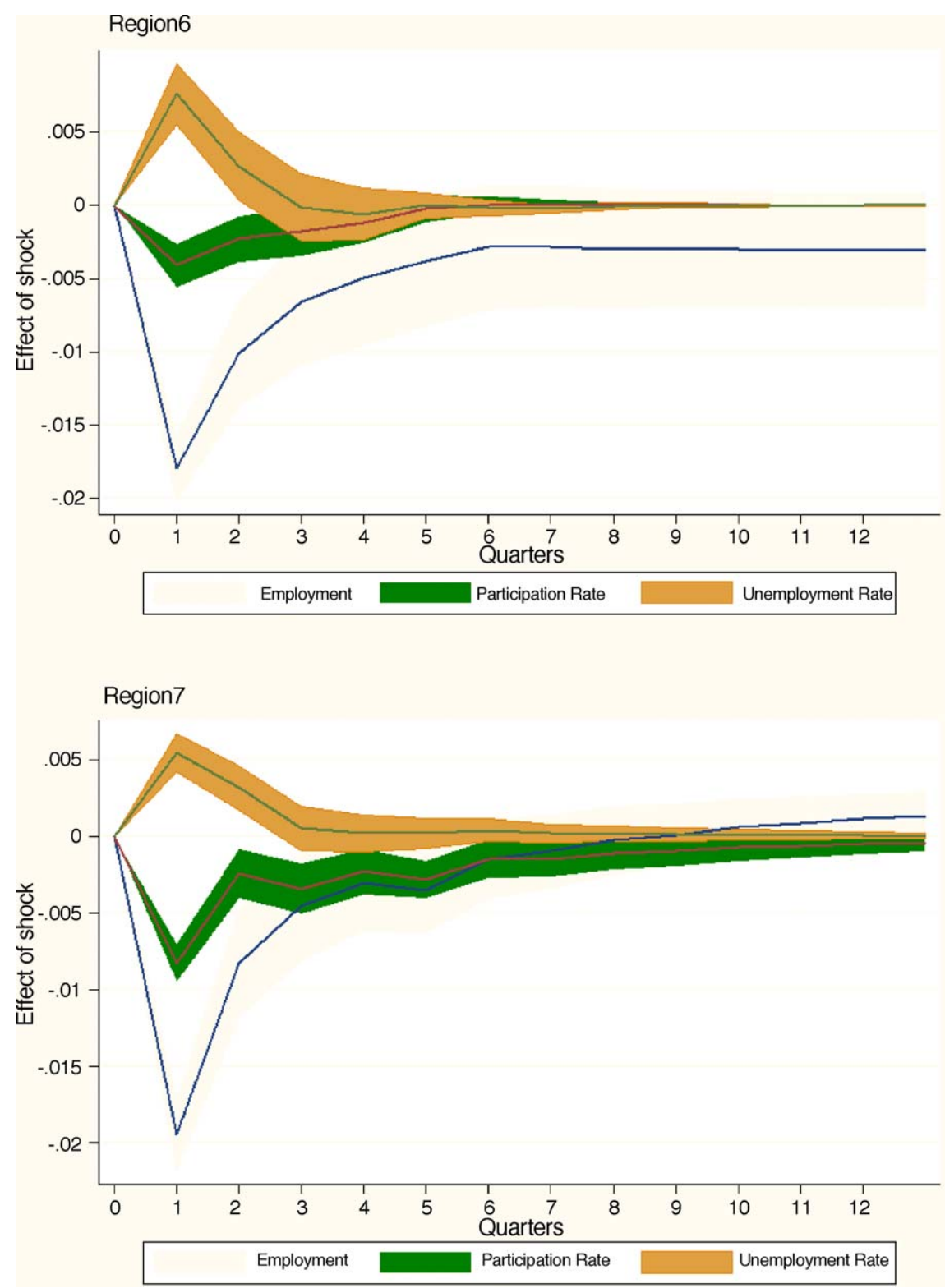

Fig. 9. (Continued)

We can run the same exercise but pooling all the regions in one large system. In this case we control regions by using dummy variables, $D_{i}$, one for each region:

$$
\begin{gathered}
\Delta e_{i t}=\alpha_{10}+\beta_{i} D_{i}+\alpha_{11}(L) \Delta e_{i, t-1}+\alpha_{12}(L) l e_{i, t-1}+\alpha_{13}(L) l p_{i, t-1}+\varepsilon_{i e t}, \\
l e_{i t}=\alpha_{20}+\gamma_{i} D_{i}+\alpha_{21}(L) \Delta e_{i, t}+\alpha_{22}(L) l e_{i, t-1}+\alpha_{23}(L) l p_{i, t-1}+\varepsilon_{i u t}, \\
l p_{i t}=\alpha_{30}+\delta_{i} D_{i}+\alpha_{31}(L) \Delta e_{i, t}+\alpha_{32}(L) l e_{i, t-1}+\alpha_{33}(L) l p_{i, t-1}+\varepsilon_{i p t}
\end{gathered}
$$



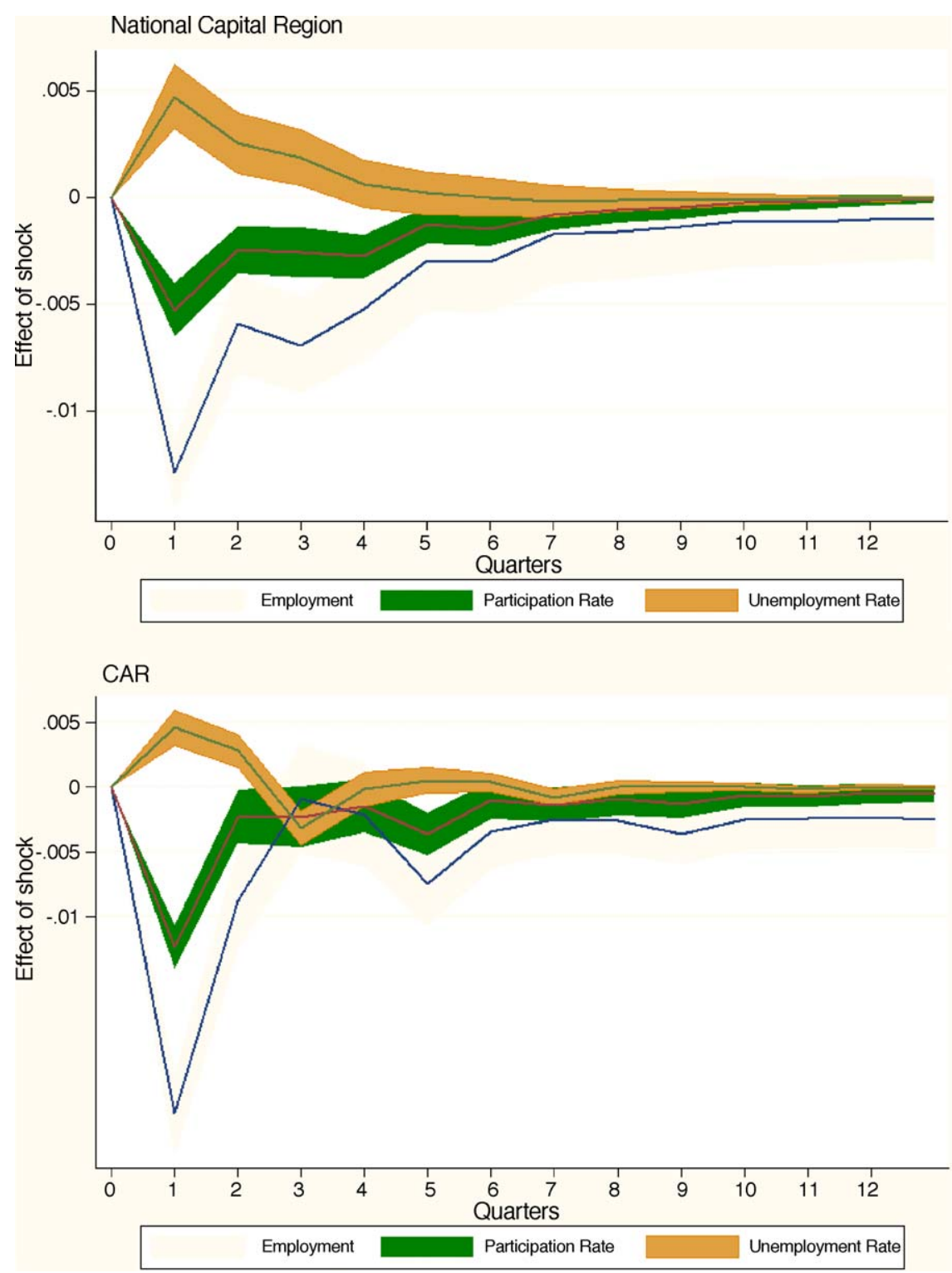

Fig. 9. (Continued)

The results of the pooled estimation are presented in Fig. 10. We observe many interesting facts in this graph. First of all, the dynamic evolution of unemployment and participation rates look very much like the ones in high minimum wage regions. It takes very long (almost 3 years) for the unemployment and the participation rate to recover from a negative shock. On the other hand employment do not recover even after many quarters. On the statistical side we can see that the confidence intervals for the impulse response functions have narrowed, as it was expected since pooling the data increases the number of usable observations. 

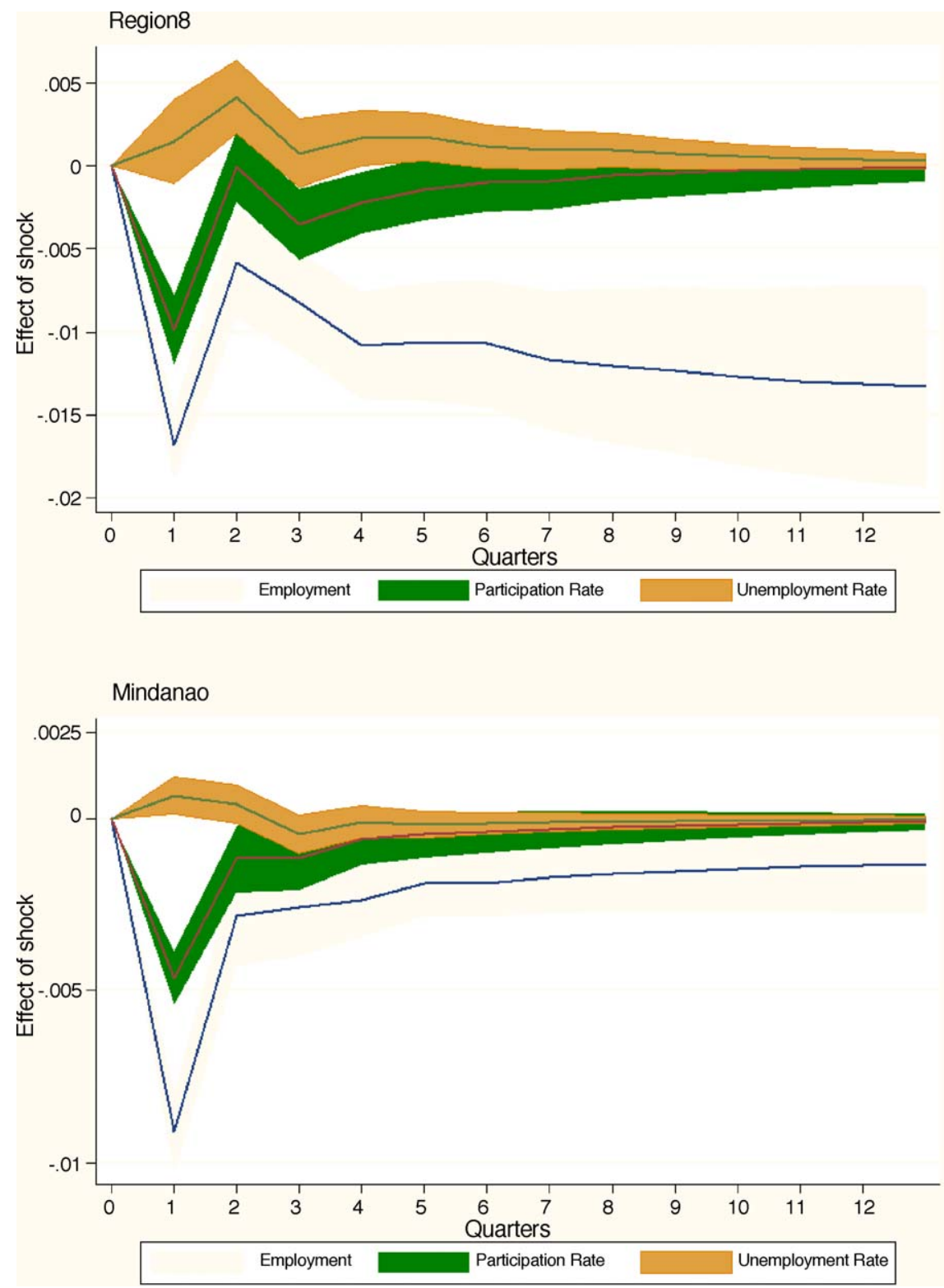

Fig. 9. (Continued).

From the estimation of the pooled model we obtain that, in the first quarter, a negative shock of $1 \%$ is reflected in an increase of unemployment of $0.32 \%$ points, and a reduction in the participation rate of $0.67 \%$ points. In terms of changes in the number of workers, a reduction in employment of one worker in the initial quarter is associated with an increase of unemployment of 0.06 workers, a decrease in participation of 0.23 workers and an implied net migration of 0.71 workers. 


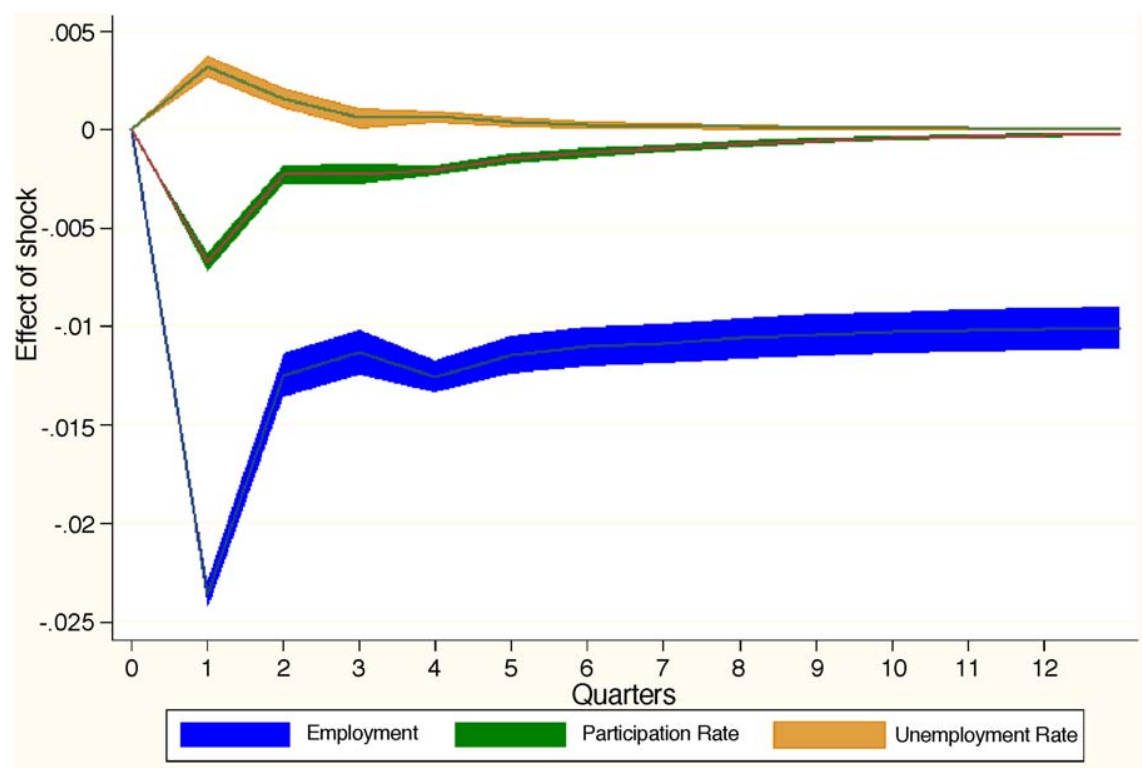

Source: Authors' calculation based on the system of equations described in the text. All the regions are used in the estimation. Bands of one standard error are shown around each line.

Fig. 10. Response of employment, unemployment, and labor force participation to an employment shock. Pooling regions.

\section{The regional dimension of underemployment}

In the introduction we pointed out that the labor market of the Philippines is characterized by a rate of unemployment and unemployment higher than the average of the other countries of its economic area. Section 4 discusses the evolution of unemployment after a negative shock. In this section we analyze the microeconomic determinants of underemployment. The National

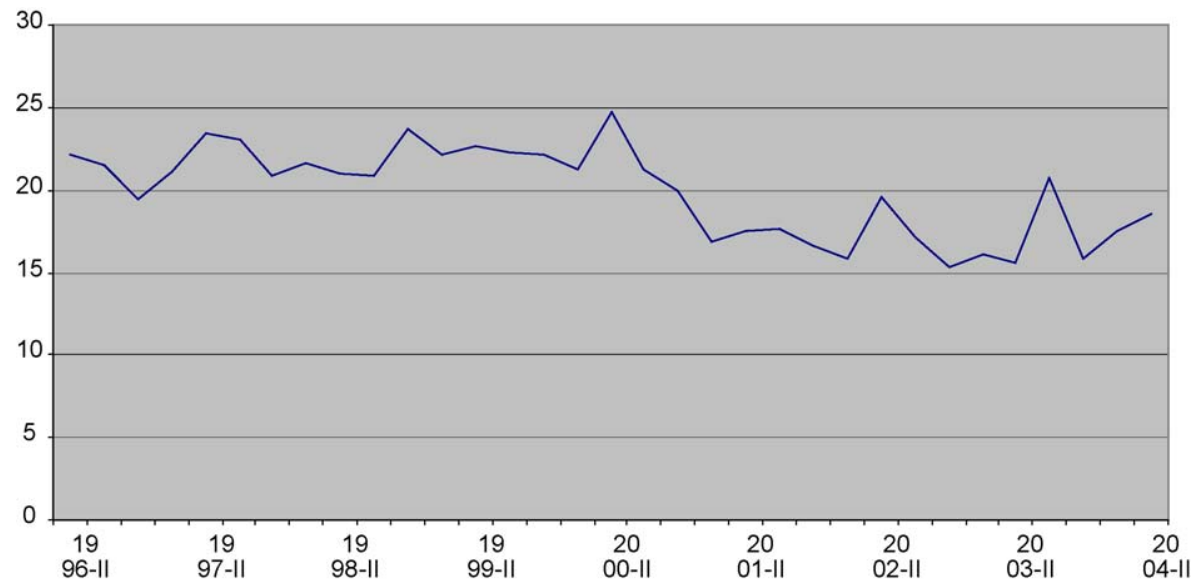

Fig. 11. Underemployment rate. 
Table 7

Determinants of the probability of being underemployed

\begin{tabular}{|c|c|c|c|c|c|c|c|c|}
\hline & \multicolumn{4}{|c|}{ All employed } & \multicolumn{4}{|c|}{ Employed heads } \\
\hline & OR & $z$ & OR & $z$ & OR & $z$ & OR & $z$ \\
\hline Age & 0.99 & -8.98 & 0.99 & -12.30 & 0.98 & -29.90 & 0.98 & -34.58 \\
\hline Male & 1.51 & 53.75 & 1.56 & 56.84 & 1.20 & 9.72 & 1.22 & 10.21 \\
\hline Urban & 0.76 & -36.89 & 0.84 & -22.12 & 0.77 & -23.95 & 0.83 & -15.30 \\
\hline Prinog & 1.67 & 20.57 & 1.29 & 9.75 & 1.87 & 18.64 & 1.31 & 7.61 \\
\hline Prigrad & 1.53 & 16.94 & 1.19 & 6.70 & 1.70 & 15.95 & 1.19 & 4.82 \\
\hline Secnog & 1.45 & 14.59 & 1.10 & 3.68 & 1.74 & 16.00 & 1.22 & 5.46 \\
\hline Secgrad & 1.23 & 8.33 & 1.02 & 0.75 & 1.31 & 8.02 & 0.98 & -0.55 \\
\hline Colnog & 1.16 & 5.67 & 0.91 & -3.48 & 1.22 & 5.64 & 0.87 & -3.72 \\
\hline Colgrad & 0.77 & -9.65 & 0.61 & -17.74 & 0.79 & -6.07 & 0.56 & -14.77 \\
\hline dyear & 0.95 & -6.10 & 0.95 & -6.41 & 0.92 & -6.92 & 0.92 & -7.27 \\
\hline $\mathrm{d} 2$ & 1.16 & 11.59 & 1.16 & 11.66 & 1.14 & 6.90 & 1.14 & 6.85 \\
\hline $\mathrm{d} 3$ & 1.11 & 8.32 & 1.12 & 8.55 & 1.13 & 6.33 & 1.13 & 6.44 \\
\hline $\mathrm{d} 4$ & 1.03 & 2.07 & 1.03 & 2.35 & 1.04 & 1.79 & 1.04 & 1.96 \\
\hline Self & 1.01 & 1.80 & 1.03 & 4.08 & 0.91 & -8.06 & 0.93 & -6.09 \\
\hline Region 2 & & & 1.53 & 17.37 & & & 1.41 & 8.82 \\
\hline Region 3 & & & 0.66 & -17.75 & & & 0.65 & -11.66 \\
\hline Region 4 & & & 1.41 & 17.12 & & & 1.50 & 12.69 \\
\hline Region 5 & & & 2.83 & 47.01 & & & 3.14 & 33.14 \\
\hline Region 6 & & & 1.73 & 25.32 & & & 1.85 & 17.93 \\
\hline Region 7 & & & 0.76 & -10.72 & & & 0.76 & -6.84 \\
\hline Region 8 & & & 2.06 & 32.07 & & & 2.10 & 21.00 \\
\hline Region 9 & & & 1.20 & 7.23 & & & 1.15 & 3.64 \\
\hline Region 10 & & & 2.10 & 33.49 & & & 2.43 & 25.14 \\
\hline Region 11 & & & 1.88 & 28.29 & & & 1.92 & 18.66 \\
\hline Region 12 & & & 2.12 & 31.04 & & & 2.14 & 20.27 \\
\hline NCR & & & 0.91 & -4.02 & & & 0.96 & -1.08 \\
\hline CAR & & & 1.14 & 5.14 & & & 1.09 & 2.14 \\
\hline ARMM & & & 0.63 & -15.86 & & & 0.57 & -13.35 \\
\hline Caraga & & & 1.79 & 23.58 & & & 1.99 & 18.18 \\
\hline$P($ regions $=0)$ & & & 0.00 & & & & 0.00 & \\
\hline$\%$ Correct & 82.9 & & 82.9 & & 80.4 & & 80.4 & \\
\hline$N$ & 576680 & & 576680 & & 233474 & & 233474 & \\
\hline
\end{tabular}

Statistics Office of the Philippines defines underemployed persons as "all employed persons who express the desire to have additional hours of work in their present job or an additional job, or to have a new job with longer working hours." The data corresponding to the second quarter of 2005 , sets the underemployment rate at $26.1 \%$ (3.7 points over the rate of the first quarter of 2002). This rate amount for close to 7 millions of workers. Fig. 11 shows the evolution of the rate of underemployment. During 2001 and 2002 there was a tendency towards the reduction of underemployment, although the second quarter of 2005 has witnessed an steep increase.

The literature has proposed several factors that can potentially be relevant to explain the underemployment status and different ways to deal with the specification of hours restrictions. ${ }^{21}$

${ }^{21}$ See for instance Ruíz-Quintanilla and Claes (1996), Ham (1982), Doiron (2003) or Dickens and Lundberg (1993). 


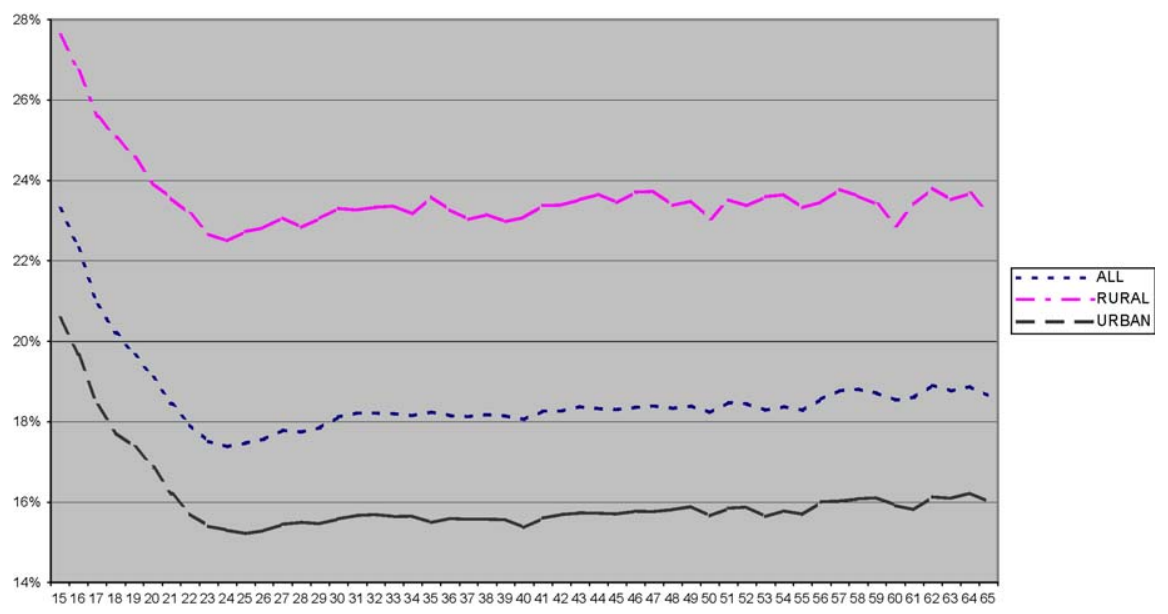

Fig. 12. Adjusted probability of underemployment by age and urbanity.

They are for the most part consistent with the characteristics that have been examined in other labor market studies, for instance on unemployment. Table 7 presents a logit estimation of the probability of being underemployed. The relevant variables include age, education, gender, urbanity and region plus a dummy variable for year and quarter of the observation. The data come from the Labor Force Survey of 2001 and 2002. We only consider ages between 15 and 65 years old. Columns 1 and 2 present the estimation using all the observations with and without the regional dummies. Columns 3 and 4 run the same logistic regression but only for head of the households.

The variables include a dummy variable for male, urbanity, primary undergraduate (prinog), primary graduate (prigrad), secondary undergraduate (secnog), secondary graduate (secgrad), college undergraduate (colnog), college graduate (colgrad), year (2002), quarter (d2, d3 and d4), self-employed (self) and each of the different regions of Philippines. All the coefficients have the expected sign. The results indicate that age has a negative effect on the probability of being underemployed but the odds ratio is very close to 1 . In column 1 the probability of underemployment of men is 1.55 times the probability of women. By contrast, Ruíz-Quintanilla and Claes (1996) find no significant effect of age or gender on the probability of underemployment among young adults. However, we should notice that their study refers only to young adults and, therefore, there is very low variability on ages. Additionally, as RuízQuintanilla and Claes (1996) recognize, they were unable to balance gender within occupational groups which implies that their result with respect to gender should be taken with care.

The probability of underemployment in urban areas is 0.77 times the one of rural areas. It is interesting to notice the monotonic decrease in the probability of underemployment with the level of education. This result is identical to the negative relationship between educational level and underemployment reported in Ruíz-Quintanilla and Claes (1996). There is only one exception: the case of college graduates. This result is identical to the one reported by RuízQuintanilla and Claes (1996). ${ }^{22}$

\footnotetext{
${ }^{22}$ Ruíz-Quintanilla and Claes (1996): "the results show that educational level, with the one exception of university level education, has a significant influence on patterns of underemployment."
} 
The year dummy indicates a reduction in the rate of underemployment over time in the sample period. There is also a clear seasonal pattern in underemployment as shown by the significant effect of the coefficient of the quarter dummy with respect to the first quarter. This effect was also clear in Fig. 11. Finally, the self-employed do not have a higher probability of underemployment than the rest of the workers.

In column 2 we report the estimation once we include as explanatory variables the regional dummies. The results are basically the same. The only difference is the statistical significance of the self-employment indicator in the explanation of underemployment. On the other hand the test statistic for the significance of the regional dummies delivers an $F$-value of 6775.5 which implies that all the dummies are jointly significantly different from 0 . The regions with the lowest probability of underemployment are Central Luzon, Central Visayas, the National Capital Region and the ARMM. Ruíz-Quintanilla and Claes (1996) report also a significant result for their Southern Europe dummy, which correspond to our regional effects.

Column 3 present the estimation of a logit model but only for the sample of heads of family who work. The sample is reduced to half the observations of the previous columns. However, the results are basically unchanged. Only the size of some coefficients change. For instance men are less likely to be underemployed, in relation with women, if they are head of the family than in the general sample of working population. In addition, the odds of underemployment for the different levels of education increase with respect to the no grade completed group. The inclusion of the regional dummies do not alter the conclusions drawn previously.

Fig. 12 presents the adjusted underemployment by age and urban/rural location. From the estimation in Table 4 it is clear that the rural line goes above the urban one. However, the interesting fact shown in Fig. 12 is that even though underemployment decreases rapidly with age in the initial working years, it quickly stalls and stays at that level for the rest of the working life. Therefore, it cannot be claimed that underemployment is, like in many other countries, simply a phenomenon that disappear with aging.

\section{Conclusions}

The labor market of the Philippines is quite special compare with the other markets of its geographical region. The unemployment rate of Philippines is higher than the one observed in other South Asian and Pacific countries with similar level of development. Its persistence is also high compare with other countries and across regions of Philippines. In addition the level of underemployment is also quite high. However, across Philippines' regions we observe very large differences in terms of the basic labor market indicators.

The objective of the paper is to provide some evidence on the dynamic adjustment of Philippines' regional labor market to shocks. The response of labor markets to negative shocks is very similar to the findings reported by Blanchard and Katz (1992). The initial impact is an increase of the unemployment rate and a decrease of the participation rate and employment. Over time the participation and unemployment rates return to their pre-shock levels while employment continues below for some time. However, there are important regional differences. In the National Capital Region it takes many quarter for the unemployment and the participation rates to go back to their pre-shock level. The same is true for the case of Central Luzon. We argue that the high minimum wage of both regions may be the source of this slow adjustment. Obviously the effect of minimum wages is combines with the migration from other regions towards the capital. 
This process speeds up the adjustment in the other regions and reduces the speed of adjustment in the National Capital Region. A sign of this effect can be found in the persistent reduction of employment in many regions after a negative shock and the recovery of the employment level in the National Capital Region. ${ }^{23}$

The second part of the article analyzes the determinants underemployment among Philippines' workers. Among them the most important are gender, urban location, education and region. Conditional on all this variables age has a very weak effect on the probability of underemployment. In fact, the adjusted probability of underemployment decreases quickly for young workers although it reaches a minimum at 24 years old and, afterward, it remains quite stable. This means that, opposite to what happen in other countries, the underemployment in Philippines is not simply a matter of age.

\section{Acknowledgements}

I thank C. Goh, A. Ciccone, M. Ho and two anonymous referees for very useful comment. Giovanni Ursino and Davide Debortoli provided excellent research assistance. Financial support from the Spanish National Science Foundation Grant SEC2004-03619 and the World Bank is gratefully acknowledged.

\section{Appendix A. Regional aggregation}

\begin{tabular}{ll}
\hline Code & Regions included \\
\hline Region 1 & Ilocos \\
Region 2 & Cagayan Valley \\
Region 3 & Central Luzon \\
Region 4 & Calabarzon and Mimaropa \\
Region 5 & Bicol \\
Region 6 & Western Visayas \\
Region 7 & Central Visayas \\
Region 8 & Eastern Visayas \\
Mindanao & Western (Region 9), Northern (Region 10), Southern (Region 11) and Central (Region12) \\
NCR & Mindano, ARMM and CARAGA \\
CAR & National Capital Region, Manila \\
\hline
\end{tabular}

Notice the need for special aggregation after 2002. At this point there is a redefinition of the regions. We do not have information of the provinces in the Labor Force Survey files and, therefore, the only chance is to propose and alternative definition of regions. The administrative changes in the definition of the regions that took place in 2002 are the following:

1. Region IV is divided into two regions: Calabarzon (IV-A) and Mimaropa (IV-B). Not only that but also the province of Aurora goes from Regions IV to III.

2. Regions IX-XII change names and redefine the provinces that are included in them. The following table shows the correspondence between regions pre- and post-2002.

\footnotetext{
${ }^{23}$ This effect is not exclusive of this region.
} 


\begin{tabular}{|c|c|c|}
\hline Region02 & Province & Region Pre02 \\
\hline I & Ilocos Norte & $\mathrm{I}$ \\
\hline I & Ilocos Sur & I \\
\hline I & La Union & I \\
\hline I & Pangasinan & $\mathrm{I}$ \\
\hline II & Batanes & II \\
\hline II & Cagayan & II \\
\hline II & Isabela & II \\
\hline II & Nueva Vizcaya & II \\
\hline II & Quirino & II \\
\hline III & Aurora & IV \\
\hline III & Bataan & III \\
\hline III & Bulacan & III \\
\hline III & Nueva Ecija & III \\
\hline III & Pampanga & III \\
\hline III & Tarlac & III \\
\hline III & Zambales & III \\
\hline IV-A & Batangas & IV \\
\hline IV-A & Cavite & IV \\
\hline IV-A & Laguna & IV \\
\hline IV-A & Quezon & IV \\
\hline IV-A & Rizal & IV \\
\hline IV-B & Marinduque & IV \\
\hline IV-B & Occidental Mindoro & IV \\
\hline IV-B & Oriental Mindoro & IV \\
\hline IV-B & Palawan & IV \\
\hline IV-B & Romblon & IV \\
\hline $\mathrm{V}$ & Albay & $\mathrm{V}$ \\
\hline $\mathrm{V}$ & Camarines Norte & $\mathrm{V}$ \\
\hline $\mathrm{V}$ & Camarines Sur & $\mathrm{V}$ \\
\hline $\mathrm{V}$ & Catanduanes & V \\
\hline $\mathrm{V}$ & Masbate & $\mathrm{V}$ \\
\hline $\mathrm{V}$ & Sorsogon & $\mathrm{V}$ \\
\hline VI & Aklan & VI \\
\hline VI & Antique & VI \\
\hline VI & Capiz & VI \\
\hline VI & Guimaras & VI \\
\hline VI & Iloilo & VI \\
\hline VI & Negros Occidental & VI \\
\hline VII & Bohol & VII \\
\hline VII & Cebu & VII \\
\hline VII & Siquijor & VII \\
\hline VII & Negros Oriental & VII \\
\hline VIII & Biliran & VIII \\
\hline VIII & Eastern Samar & VIII \\
\hline VIII & Leyte & VIII \\
\hline VIII & Northern Samar & VIII \\
\hline VIII & Western Samar & VIII \\
\hline VIII & Southern Leyte & VIII \\
\hline IX & Zamboanga Sibugay & IX \\
\hline IX & Zamboanga Del Norte & IX \\
\hline IX & zamboanga Del Sur & IX \\
\hline $\mathrm{X}$ & Bukidnon & $\mathrm{X}$ \\
\hline $\mathrm{X}$ & Camiguin & $\mathrm{X}$ \\
\hline $\mathrm{X}$ & Lanao Del Norte & XII \\
\hline
\end{tabular}


Appendix A (Continued)

\begin{tabular}{lll}
\hline Region02 & Province & Region Pre02 \\
\hline X & Misamis Occidental & X \\
X & Misamis Oriental & X \\
XI & Compostela Valley & XI \\
XI & Davao Del Norte & XI \\
XI & Davao Del Sur & XI \\
XI & Davao Oriental & XI \\
XII & North Cotabato & XII \\
XII & Sarangani & XI \\
XII & South Cotabato & XI \\
XII & Sultan Kudarat & XII \\
XIII & Agusan Del Norte & XIII \\
XIII & Agusan Del Sur & XIII \\
XIII & Surigao Del Norte & XIII \\
XIII & Surigao Del Sur & XIII \\
ARMM & Basilan & IX \\
ARMM & Lanao Del Sur & ARMM \\
ARMM & Maguindanao & ARMM \\
ARMM & Sulu & ARMM \\
ARMM & Tawi-Tawi & ARMM \\
CAR & Abra & CAR \\
CAR & Apayao & CAR \\
CAR & Buenguet & CAR \\
CAR & Ifugao & CAR \\
CAR & Kalinga & CAR \\
CAR & Mt Province & CAR \\
\hline & &
\end{tabular}

The changes of Aurora and Basilan, that affect regions III, IV, IX and ARMM do not seem to make a big change in the results and, therefore, we have kept the original regions without modification. However, the changes in regions X, XI and XII are very important as we can see in the graph where they are separately. For this reason we have decided to create a fictitious region called Rest of Mindanao where we include these three regions.

\section{References}

Bayoumi, T., \& Prasad, E. (1995). Currency unions, economic fluctuations and adjustment: Some empirical evidence. CEPR Discussion Paper 1172.

Blanchard, O., \& Wolfers, J. (2000). The role of shocks and institutions in the rise of European unemployment: the aggregate evidence. Economic Journal, 110, C1-C33.

Blanchard, O., \& Katz, L. (1992). Regional evolutions. Brookings Papers on Economic Activity, 1, 1-61.

Blanchard, O. (2006). European unemployment. Economic Policy, 7-59.

Decressing, J., \& Fatas, A. (1995). Regional labor market dynamics in Europe. European Economic Review, 39, 16271655.

Dickens, W., \& Lundberg, S. (1993). Hours restrictions and labor supply. International Economic Review, 34(1), 169192.

Doiron, D. (2003). Is underemployment due to labor hoarding? Evidence from Australian workplace industrial relations survey. Economic Record, 79(2), 306-323.

Ham, J. (1982). Estimation of a labor supply model with censoring due to unemployment and underemployment. Review of Economic Studies, 49, 335-354. 
Manlagñit, M. (2004). The role of other economically active household members in poverty alleviation. Discussion Paper 2004-03, PIDS.

Orbeta, A. (2002). Education, labor market and development: A review of the trends and issues in the Philippines for the past 25 years. Discussion Paper 2002-19, PIDS.

Ruíz-Quintanilla, S., \& Claes, R. (1996). Determinants of underemployment of young adults: A multi-country study. Industrial and Labor Relationships Review, April.

Shield, M., \& Novak, J. (2000). Dynamic labor response to employment shocks: A country level analysis. Mimeo. 